\title{
Measuring the 3-D wind vector with a weight-shift microlight aircraft
}

\author{
S. Metzger ${ }^{1,2}$, W. Junkermann ${ }^{1}$, K. Butterbach-Bahl ${ }^{1}$, H. P. Schmid ${ }^{1}$, and T. Foken ${ }^{3}$ \\ ${ }^{1}$ Karlsruhe Institute of Technology, Institute for Meteorology and Climate Research, Garmisch-Partenkirchen, Germany \\ ${ }^{2}$ Chinese Academy of Sciences, Institute of Atmospheric Physics, Beijing, China \\ ${ }^{3}$ University of Bayreuth, Department of Micrometeorology, Bayreuth, Germany
}

Received: 20 January 2011 - Published in Atmos. Meas. Tech. Discuss.: 28 February 2011

Revised: 29 June 2011 - Accepted: 7 July 2011 - Published: 19 July 2011

\begin{abstract}
This study investigates whether the 3-D wind vector can be measured reliably from a highly transportable and low-cost weight-shift microlight aircraft. Therefore we draw up a transferable procedure to accommodate flow distortion originating from the aircraft body and -wing. This procedure consists of the analysis of aircraft dynamics and seven successive calibration steps. For our aircraft the horizontal wind components receive their greatest single amendment ( $14 \%$, relative to the initial uncertainty) from the correction of flow distortion magnitude in the dynamic pressure computation. Conversely the vertical wind component is most of all improved $(31 \%)$ by subsequent steps considering the 3-D flow distortion distribution in the flow angle computations. Therein the influences of the aircraft's trim (53\%), as well as changes in the aircraft lift (16\%) are considered by using the measured lift coefficient as explanatory variable. Three independent lines of analysis are used to evaluate the quality of the wind measurement: (a) A wind tunnel study in combination with the propagation of sensor uncertainties defines the systems input uncertainty to $\approx 0.6 \mathrm{~m} \mathrm{~s}^{-1}$ at the extremes of a $95 \%$ confidence interval. (b) During severe vertical flight manoeuvres the deviation range of the vertical wind component does not exceed $0.3 \mathrm{~m} \mathrm{~s}^{-1}$. (c) The comparison with ground based wind measurements yields an overall operational uncertainty (root mean square error) of $\approx 0.4 \mathrm{~m} \mathrm{~s}^{-1}$ for the horizontal and $\approx 0.3 \mathrm{~m} \mathrm{~s}^{-1}$ for the vertical wind components. No conclusive dependence of the uncertainty on the wind magnitude $\left(<8 \mathrm{~m} \mathrm{~s}^{-1}\right)$ or true airspeed (ranging from $23-30 \mathrm{~m} \mathrm{~s}^{-1}$ ) is found. Hence our analysis provides the necessary basis to study the wind measurement precision and spectral quality, which is prerequisite for reliable Eddy-Covariance flux measurements.
\end{abstract}

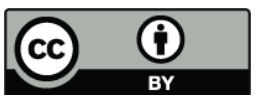

Correspondence to: W. Junkermann (wolfgang.junkermann@kit.edu)

\section{Introduction}

In environmental science, spatial representativeness of measurements is a general problem. The limited coverage of ground based measurements requires strategies to better understand spatial patterns (e.g., Baldocchi et al., 2001; Beyrich et al., 2006). Here airborne measurements are capable of supplementing and extrapolating ground based information (e.g., Lenschow, 1986; Desjardins et al., 1997; Mauder et al., 2008). However, to date manned platforms, such as fixedwing aircraft (FWA, a summary of all notation is provided in Supplement C, see Sect. 3) and helicopters, are expensive to operate. Furthermore, their application is often not possible in settings such as remote areas beyond the range of an airfield. Here small size unmanned aerial vehicles are of use. These allow the measurement of a limited range of variables, such as temperature, humidity and wind vector (e.g., Egger et al., 2002; Hobbs et al., 2002; van den Kroonenberg et al., 2008). However due to payload constraints, they do not allow a comprehensive sensor package. A weightshift microlight aircraft (WSMA) may provide a low-cost and easily transportable alternative, which also places a minimal demand on infrastructure in the measurement location. After successfully applying a WSMA to aerosol and radiation transfer studies (e.g., Junkermann, 2001, 2005), the possibility of 3-D wind vector measurement from WSMA shall be explored. The underlying motivation is to work towards Eddy-Covariance (EC) flux measurements in the atmospheric boundary layer (ABL).

The determination of the 3-D wind vector from an airborne, i.e. moving platform, requires a high degree of sophistication. Specially designed probes enable the measurement of the 3-D turbulent wind field with respect to the aircraft (e.g. Brown et al., 1983; Crawford and Dobosy, 1992). At the same time the aircraft's movement with respect to the earth must be captured (e.g. Lenschow, 1986; Kalogiros and Wang, 2002a). A total of 15 measured quantities are involved

Published by Copernicus Publications on behalf of the European Geosciences Union. 
in the computation of the 3-D wind vector (Supplement A), and consequently a similar number of potential uncertainty sources need to be considered. Furthermore, flow distortion by the aircraft itself can affect the measurement (e.g. Crawford et al., 1996; Kalogiros and Wang, 2002b; Garman et al., 2008). This complexity led to a number of quantitative uncertainty assessments of the wind measurement from aircraft, of which a few shall be mentioned here. While the carriers are commonly FWA, they cover a wide range, from single-engined light aircraft (e.g. Crawford and Dobosy, 1992) to twin-engined business jet (Tjernström and Friehe, 1991, e.g.) and quad-engined utility aircraft (e.g. Khelif et al., 1999). A similar variety of methodologies is used for the individual proof-of-concept. Widespread are uncertainty propagation of sensor uncertainties (e.g. Tjernström and Friehe, 1991; Crawford and Dobosy, 1992; Garman et al., 2006) and the analysis of specific flight manoeuvres (e.g. Tjernström and Friehe, 1991; Williams and Marcotte, 2000; Kalogiros and Wang, 2002a). Probably due to the higher infrastructural demand, wind tunnel studies (e.g. Garman et al., 2006), comparison to ground based measurements (e.g. Tjernström and Friehe, 1991) and aircraft intercomparisons (e.g. Khelif et al., 1999) are less common. Often statistical measures are used to express uncertainty, such as repeatability (e.g. $0.03 \mathrm{~m} \mathrm{~s}^{-1}$, Garman et al., 2006), deviation range (e.g. 0.4-0.6 $\mathrm{m} \mathrm{s}^{-1}$, Williams and Marcotte, 2000), median differences (e.g. $0.1 \pm 0.4 \mathrm{~m} \mathrm{~s}^{-1}$, Khelif et al., 1999), or root mean square error (e.g. $\geq 0.1 \mathrm{~m} \mathrm{~s}^{-1}$ at $\leq 2 \mathrm{~m} \mathrm{~s}^{-1}$ deviation range, Kalogiros and Wang, 2002a).

The EC technique (e.g., Kaimal and Finnigan, 1994) relies upon the precise measurement of atmospheric fluctuations, including the fluctuations of the vertical wind. Measured from aircraft, the determination of the wind vector requires a sequence of thermodynamic and trigonometric equations (Supplement A). These ultimately define the wind component's frame of reference. Yet, owing to its flexible wingand aircraft architecture, the dynamics and flow distortion of the WSMA are likely more complex than those of FWA. Therefore the use of well established wind vector algorithms for FWA requires adaptation and correction. Consequently this study first and foremost investigates the feasibility and reliability of the wind measurement from WSMA. Based on these findings the measurement precision will be addressed in a successive study. The WSMA's overall measurement uncertainty was quantified by one standard deviation $(\sigma)$ for sensor uncertainties provided by the manufacturers (combined effects of temperature dependence, gain error, nonlinearity), and one root mean square error (RMSE) for uncertainties from comparison experiments (including the uncertainty of the external reference, where applicable). Due to their analogous role in variance statistics, $\sigma$ and RMSE are both referred to with one $\sigma$ for convenience.

At the outset of this study the use of computational fluid dynamics was envisaged. The assessment was that, with great effort, such model could describe the mean aerodynamic properties of the WSMA. The challenge of the wind measurement from WSMA however comprises from the sources of variability. Consequently preference was given to a detailed experimental study. After introducing the WSMA and outlining its physical properties, the sensor package for this study is presented. Following the analysis of the aircraft's dynamics, a toolbox is derived for the calibration of the 3-D wind vector measurement and assessment of its uncertainty. It consists of a wind tunnel study, uncertainty propagation and in-flight manoeuvres. The toolbox is used to customize a wind vector algorithm for use with the WSMA. To evaluate this procedure, the final calibration is applied to measurements in the ABL. Wind measurements from the WSMA are compared to simultaneous ground based measurements from sonic detection and ranging (SODAR) and tall tower sonic- and cup anemometer and vane measurements. Based on three independent lines of analysis the overall uncertainty of the WSMA wind measurement is determined.

\section{The weight-shift microlight aircraft}

According to the safety and regulatory standards of the European Civil Aviation Conference, microlight aircraft are defined as aircraft with a maximum stall speed of $65 \mathrm{~km} \mathrm{~h}^{-1}$ and a take-off mass of no more than $450 \mathrm{~kg}$. Figure 1 shows the weight-shift microlight research aircraft D-MIFU. It consists of two distinct parts, the wing and the trike (the unit hung below the wing, containing pilot, engine and the majority of the scientific equipment). The weight-shift control system is enabled by the pilot's direct application of pitching or rolling moments to the wing via the basebar. Counterbalance is provided by the mass of the trike unit suspended below the wing. Simple procedures for certification of installations on an open aircraft allow a wide spectrum of applications as well as flexible installation of scientific equipment. At an operational airspeed of $\approx 100 \mathrm{~km} \mathrm{~h}^{-1} \mathrm{D}$ MIFU can carry a maximum of $80 \mathrm{~kg}$ scientific payload from $15 \mathrm{~m}$ a.g.l. (above ground) to $4000 \mathrm{~m}$ a.s.l. (above sea level). The full performance characteristics can be found in Junkermann (2001).

D-MIFU consists of a KISS 450 cambered wing by Air Creation, France, and the ENDURO-1150 trike manufactured by Ultraleichtflug Schmidtler, Germany. Owing to its aeroelasticity, the tailless delta wing is termed a flex-wing, contributing $\approx 15 \%$ to the aircraft weight. The primary parts of the wing structure are the leading edges joined at the nose to the keel tube, which runs the root length of the wing (Fig. 1). Stretched over upper and lower surface is a high strength polyester sail. At a span of $9.8 \mathrm{~m}$ and keel length of $2.1 \mathrm{~m}$, the wing provides a surface $(S)$ of $15.1 \mathrm{~m}^{2}$. It is put under considerable internal loads during rigging, it's form and rigidity being ensured by cross-tubes, rods and a wiring system. The basebar in front of the pilot seat is linked to 


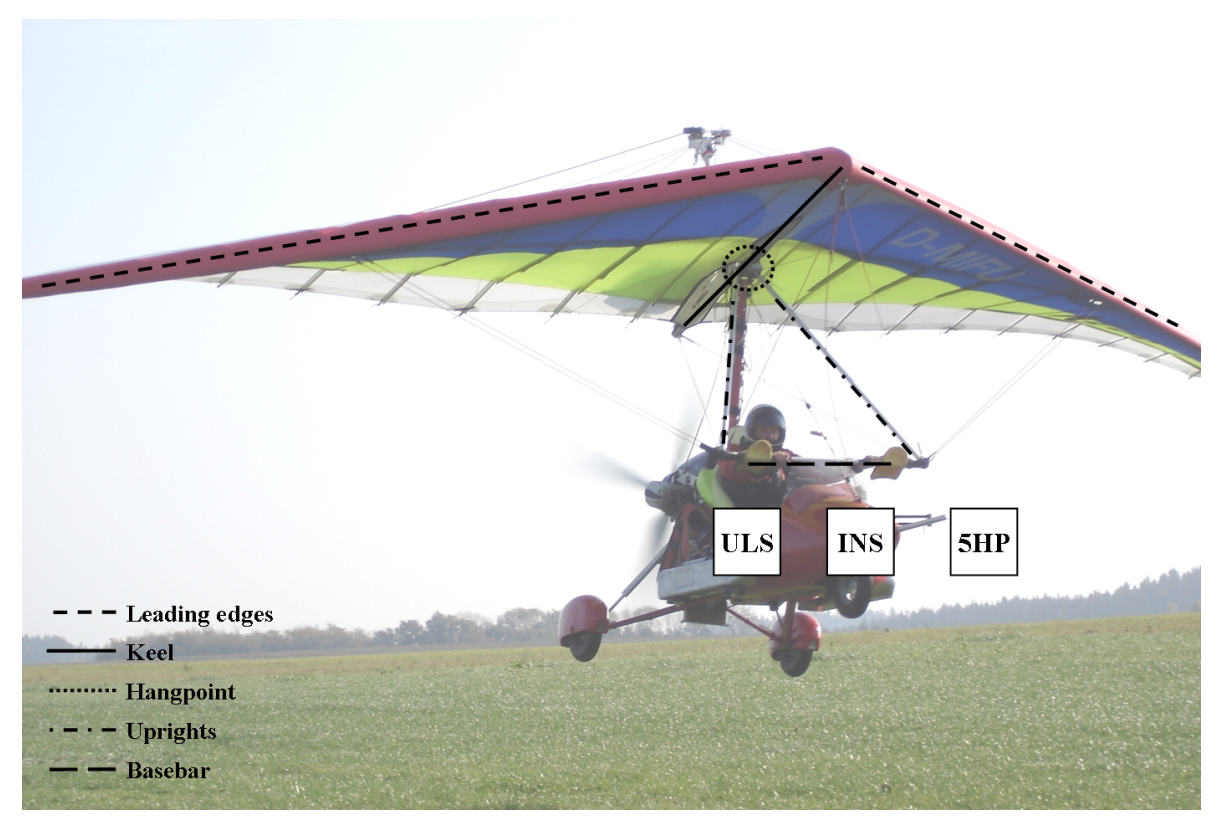

Fig. 1. Weight-shift microlight research aircraft D-MIFU, aircraft structural features are highlighted by dash-dotted lines. Sensor locations of five hole probe (5HP), inertial navigation system (INS, inside aircraft nose) and universal laser sensor (ULS, below pilot seat) are indicated. For details on the respective installations see Sect. 2.2 and Table 2. Figure 3 details the layout of the five hole probe.

the keel via two uprights and tensioned flying wires. It provides transmission of pitch and roll forces and is the primary flight control (Gratton, 2001). In the hangpoint on the wing keel the trike is attached to the wing. Since the trike is free to rotate in pitch and roll without hindrance, there is no pendular stability. In this regard the relationship of trike to wing is similar to the relationship of a trailing bomb to its carrier (e.g. HELIPOD, Bange and Roth, 1999). However trike and wing are fixed in their longitudinal axis, i.e. in the heading direction. The trike does not contribute significantly to the WSMA's lift, but represents a large portion of weight $(\approx 85 \%)$, drag, and provides all thrust through a $73 \mathrm{~kW}$ pusher engine-propeller combination. Flight stability in three axes is based on the offset of torques appearing at different locations on the wing (Cook, 1994). Torques result from wing aerodynamical effects, which sum nearest to neutral (slight nose-down torque for cambered wings) in one point along the wing's chord line, termed the wing's centre of pressure (Fig. 2). The centre of gravity, as far as the wing is concerned, is located in the hangpoint. The net aerodynamical torque is offset by an longitudinal lever arm between the centres of pressure and -gravity, determining the aircraft's trim speed (the airspeed at which the aircraft will fly steadily without pilot input). Moreover increasing airspeed will result in an aeroelastical flattening of the wing, which is in contrast to FWA. This in turn can alter the balance of torsional loads and with it the circulation about the wing (Cook and Spottiswoode, 2006).

\subsection{Physical properties}

The need to adapt wind calibration procedures designed for fixed-wing aircraft is mainly caused by two structural features of the WSMA. The trike, i.e. the turbulence measurement platform, is mobile for pitching and rolling movements below the wing. Therefore the trike-based flow- and attitude angles must be measured with high resolution, precision and accuracy. Moreover, wing aerodynamics depends on its aeroelasticity with airspeed, and varying flow distortion in front of the wing must be considered. The effects of these WSMA features are not necessarily independent of each other, and may have a different impact on the wind measurement depending on the aircraft dynamics at a particular time. Therefore the WSMA was equipped with motion sensors. On the trike these were placed in the fuselage (Inertial Navigation System, INS) and the wind measuring pressure probe ( 3 -D acceleration), extending $\approx 0.7 \mathrm{~m}$ and $\approx 3.5 \mathrm{~m}$ forward from fuselage and aft-mounted propeller, respectively (Figs. 1 and 2). Further, the wing was equipped with motion sensors in the hangpoint (3-D acceleration) and atop the wing (3-D attitude). The INS is the most reliable motion sensor (Table 2), since it integrates the complementary characteristics of global positioning system (unbiased) and inertial measurement (precise). Position and velocity are calculated from inertial measurements of 3-D acceleration and 3-D angular rate, and matched with data from two global positioning units using a Kalman filter. The INS outputs 3-D vectors of position, attitude, velocity, angular rates and acceleration. 


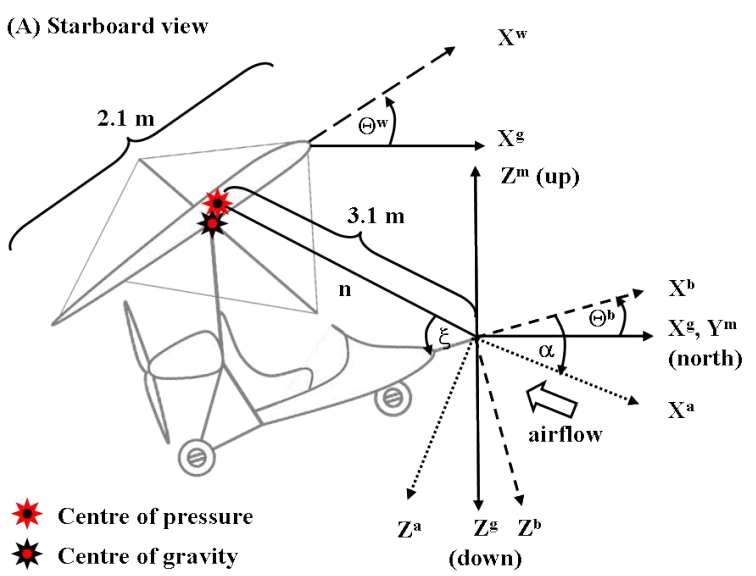

(B) Rear view

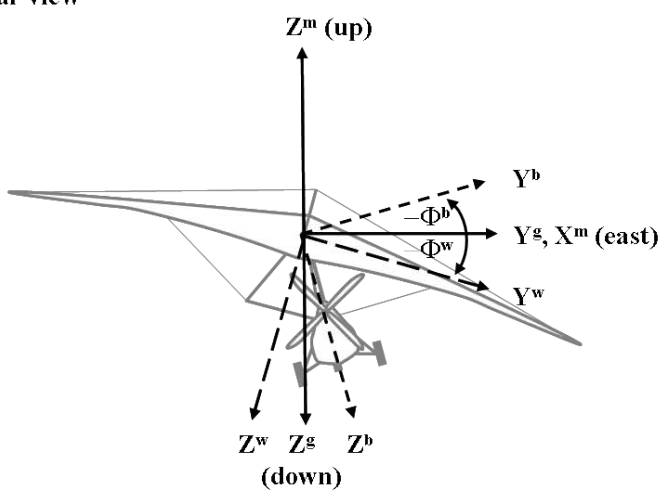

(C) Top view

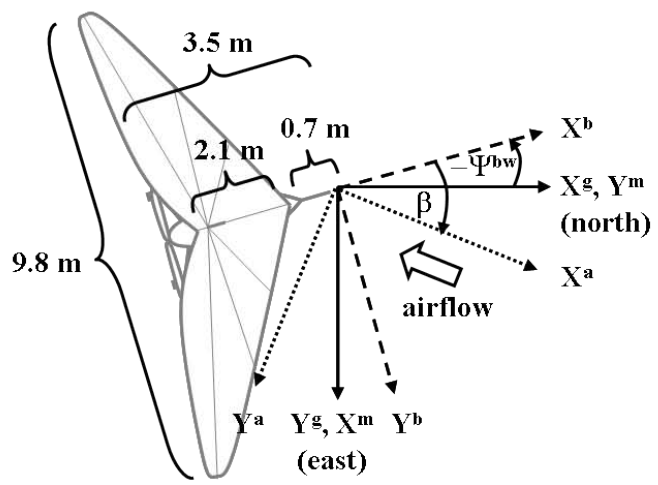

Fig. 2. Geometrical features of the weight-shift microlight aircraft and coordinate systems with axes $\mathrm{X}, \mathrm{Y}$, and $\mathrm{Z}$ used to compute the wind vector. The superscripts $a, b, g, m$ and $w$ represent, respectively, the aerodynamic-, body-, geodetic-, meteorological and wing coordinate systems (Supplement A). (A) Starboard view: Angle of attack $(\alpha)$, pitch angle $(\Theta)$, normalized radius $(n)$, wing upwash direction $(\xi)$, centre of gravity and centre of pressure. Continued on next page: (B) Rear view: Roll angle $(\Phi)$; (C) Top view: Sideslip angle $(\beta)$ and true heading $(\Psi)$. In addition the distances between five hole probe measurement and the inertial navigation system $(0.7 \mathrm{~m})$ and propeller $(3.5 \mathrm{~m})$, as well as the wing's chord length $(2.1 \mathrm{~m})$ and wingspan $(9.8 \mathrm{~m})$ are shown.
Airborne wind measurements are susceptible to distortion, since the aircraft itself is (a) a flow barrier and (b) must produce lift to remain airborne (Wyngaard, 1981; Cooper and Rogers, 1991). The aircraft's propeller, trike, and wing can be sources of flow distortion. Only little distortion from trike structural features is expected transverse to the pressure probe: the trike body is symmetric on its port and starboard side, and the pressure probe, propeller and pilot are centred on its longitudinal axis (Figs. 1 and 2). In contrast the body is asymmetric on its upside and underside, and the propeller location is $0.8 \mathrm{~m}$ higher than the pressure probe. This suggests symmetric flows in transverse, and asymmetric flows in longitudinal and vertical directions. All of which are expected to carry continuously through the pressure probe location, since the probe is rigidly fixed to the trike. This however is not the case for distortion from the WSMA wing. While the wind measurement encounters lift-induced upwash from the wing (Crawford et al., 1996; Garman et al., 2008), the trike, and with it the pressure probe, has rotational freedom in pitch and roll towards the WSMA wing. In the following we will outline the dependences of upwash generation. The amount of lift $(L)$ generated by the wing equals the aircraft's sum of vertical forces:

$L=m a^{\mathrm{g}, z}$,

with the aircraft mass $(m)$ and the vertical acceleration $\left(a^{\mathrm{g}, z}\right)$ in the geodetic coordinate system (GCS, superscript g, positive northward, eastward and downward) at the wing's centre of gravity (measured at, or dislocated to the hangpoint). Here also the aircraft control forces applied by the pilot meet. During $\mathrm{ABL}$ measurements these are primarily changes in power setting and wing pitch to adjust the aircraft altitude. For simplicity the acceleration perpendicular to the airstream was approximated by the vertical acceleration in the GCS. The maximum deviation during severe vertical manoeuvring (only used for validation) d oes not exceed $\pm 1 \%$. During level, unaccelerated flight, lift essentially equals the aircraft's weight force, but is opposite in sign. The loading factor (LF) during vertically accelerated flight is then $\mathrm{LF}=\frac{L}{\mathrm{mg}}$, the ratio of lift- to weight force with $g=9.81 \mathrm{~m} \mathrm{~s}^{-2}$. Normalizing $L$ for the airstream's dynamic pressure $\left(p_{q}\right)$ and the wing's surface area $(S)$ yields the unit-free lift coefficient $(C L)$ :

$$
\begin{array}{rlr}
C L & =\frac{1}{p_{q}} \quad \frac{L}{S} \\
& =\frac{2}{\rho v_{\text {tas }}^{2}} \quad \frac{L}{S},
\end{array}
$$

with wing loading $\left(\frac{L}{S}\right)$. Moreover $p_{q}$ in Eq. (2) can be substituted by air density $(\rho)$ and true airspeed $\left(v_{\text {tas }}\right)$. In $C L$ the wing's ability to generate lift is determined to be approximately linear with wing pitch. As a consequence of lift generation air rises in front of the wing, which is defined as upwash. Crawford et al. (1996) provide the 


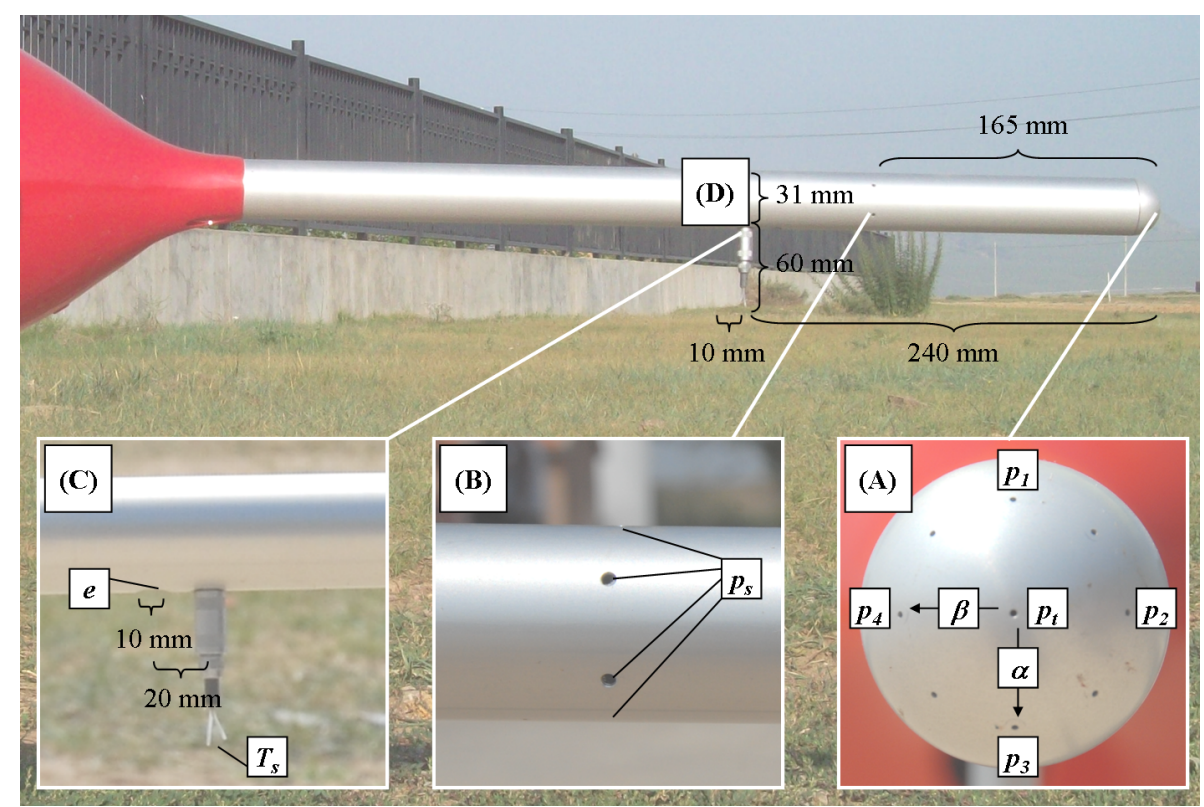

Fig. 3. Layout of the five hole probe, with letters indicating sensor locations. (A) The half sphere tip of the five hole probe, with ports for total- and differential pressure measurements. (B) Ports for static pressure measurement downstream of the half sphere. (C) Thermocouple and port for the capacitive humidity measurement. (D) Location of five hole probe 3-D acceleration sensor. Additional information is given in Sect. 2.2.

following parametrization to calculate the upwash velocity $\left(v_{\mathrm{up}}^{w}\right)$ for FWA:

$$
\begin{aligned}
v_{\text {up }}^{w} & =\frac{1}{\pi^{2} n} v_{\text {tas }} C L \\
& =\frac{1}{\pi^{2} n} \frac{v_{\text {tas }}}{p_{q}} \frac{L}{S}, \text { with } \frac{\delta \frac{v_{\text {tas }}}{p_{q}}}{\delta v_{\text {tas }}} \approx-0.3 \mathrm{hPa}^{-1} .
\end{aligned}
$$

Here $v_{\text {up }}^{w}$ is defined as the tangent on a circle with normalized radius $n$. Thereby $n$ is the separation distance from the wing's centre of pressure to the position of the pressure probe, normalized by the effective wing chord (Fig. 2). The wing upwash direction $\xi$ is then enclosed by $n$ and the trike body axis $X_{\mathrm{b}}$. Since the wing is free to rotate in pitch and roll, $v_{\text {up }}^{w}$ carries the orientation of the wing coordinate system (WCS, superscript w, positive forward, starboard, and downward). In Eq. (3) $v_{\text {up }}^{w}$ varies inversely with $n$. Furthermore $v_{\text {up }}^{w}$ can be expressed either directly proportional to $v_{\text {tas }}$ and $C L$, or directly proportional to relative airspeed $\left(\frac{v_{\text {tas }}}{p_{q}}\right)$ and $\frac{L}{S}$. Based on the functional relation between lift and upwash generation a treatment for the wind measurement from WSMA is derived in Sect. 4.1.

\subsection{Instrumentation and data processing}

Wind measurement by airborne systems is challenging. High resolution sensors are needed to determine the attitude, position, and velocity of the aircraft relative to the earth, as well as the airflow in front of the fuselage. The instrumentation involved in the wind measurement and data acquisition, including the respective manufacturers, is summarized in Table 1. A more detailed description of sensor characteristics and uncertainties is provided in Table 2, while respective locations are displayed in Figs. 1 and 3.

The principle is to resolve the meteorological wind vector from the vector difference of the aircraft's inertial velocity (recorded by the inertial navigation system) and the wind vector relative to the aircraft. To determine the latter, the aircraft was outfitted with a specially designed lightweight five hole half sphere pressure probe (5HP, e.g. Crawford and Dobosy, 1992; Leise and Masters, 1993). Figure 3 detail a shows the half sphere tip of the 5HP, with a total pressure $\left(p_{t}\right)$ port at its centre. Two additional pressure ports on each, the vertical $\left(p_{1}, p_{3}\right)$ and the horizontal axis $\left(p_{2}, p_{4}\right)$, surround the central port at an angle of $\tau=45^{\circ}$. These differential pressure readings are used to determine attack angle $(\alpha)$ and sideslip angle $(\beta)$, respectively, arrows indicate the direction of positive angular measurement. Polyetherketone tubings of $\leq 80 \mathrm{~mm}$ length and $1 \mathrm{~mm}$ inner diameter are used to connect these ports of $1.5 \mathrm{~mm}$ diameter to their respective pressure transducers. Additional (unnumbered) pressure ports at $45^{\circ}$ increments are not used in this study. Six pressure ports are located downstream of the half sphere (Fig. 3 detail $b$ ). These are ring-compensated around the circumference of the five hole probe for flow angle independent static pressure $\left(p_{\mathrm{s}}\right)$ measurement. Figure 3 detail c shows the freely suspended $50 \mu \mathrm{m}$ type $\mathrm{K}$ thermocouple for fast temperature $\left(T_{\mathrm{S}}\right)$ measurement and the $10 \mathrm{~mm}$ port for a capacitive 
Table 1. Overview of sensors and electronic instrumentation used for the wind measurement.

\begin{tabular}{llll}
\hline Component & Model & Manufacturer & Address \\
\hline Butterworth low pass filter & AF40-4BU TP & E.S.F. electronic & Göttingen, Germany \\
Electronic compass module & TCM2-20 & PNI Sensor Corporation & Santa Rosa, USA \\
Humidity sensor & SHT75 & Sensirion AG & Staefa, Switzerland \\
Industrial computer & PR-Z32-EA-ST & Diamond Systems Corporation & Newark, USA \\
Inertial navigation system & RT3102 & Oxford Technical Solutions & Upper Heyford, England \\
Pressure sensor & PCLA12X5D & Sensortechnics GmbH & Puchheim, Germany \\
Pressure sensor & SP82AL & Capto As. & Horten, Norway \\
Thermocouple & CHAL-002 & OMEGA Engineering, Inc. & Stamford, USA \\
Three-axis accelerometer & ADXL330 & Analog Devices, Inc. & Norwood, USA \\
Universal laser sensor & ULS (Second edition) & Laser Technology, Inc. & Centennial, USA \\
Operating system & Minix 2.0 & Andrew Stuart Tanenbaum & Amsterdam, Netherlands \\
\hline
\end{tabular}

humidity measurement $(e)$. Time constants of thermocouple and humidity sensor are $<0.02 \mathrm{~s}$ and $<5 \mathrm{~s}$ at $v_{\text {tas }}=27 \mathrm{~m} \mathrm{~s}^{-1}$, respectively. Humidity readings are solely used to provide the air density correction for the $v_{\text {tas }}$ computation. At a typical true airspeed of $28 \mathrm{~m} \mathrm{~s}^{-1}$ only about $30 \%$ and $15 \%$ of the dynamic- and differential pressure transducer's range is exploited, respectively. This however enables the 5HP to be used also on faster aircraft such as motorized gliders, e.g. for inter-comparison measurements. Plug- and-socket connectors with locating pins insure a repeatable location of the 5HP with respect to the INS within $<0.1^{\circ}$. The whole installation weights in at $350 \mathrm{~g}$.

$100 \mathrm{~Hz}$ temperature and pressure signals pass through hardware (analogue) four-pole Butterworth filters with $20 \mathrm{~Hz}$ cut-off frequency to filter high-frequency noise. Filter slope and frequency were chosen to allow miniaturization and comply with the system's $15 \mathrm{~Hz}$ bottleneck filter frequency of the infra-red gas analyser for EC flux calculation (not used in this study). The filter leads to a phase shift in the signal of $\approx 20 \mathrm{~ms}$, and the amplitude of a $10 \mathrm{~Hz}$ sine signal is reduced by $<1 \%$. The INS data are stored in a standalone system at a rate of $100 \mathrm{~s}^{-1}$. Remaining data streams for the wind computation are stored centrally at a rate of $10 \mathrm{~s}^{-1}$ by an in-house developed data acquisition system (embedded Institute for Meteorology and Climate Research data acquisition system, EIDAS). EIDAS is based on a ruggedized industrial computer and a real-time UNIX-like operating system. $5 \mathrm{~V}$ analogue signals at $\geq 10 \mathrm{~Hz}$ pass through a multiplexer and $\mathrm{A} / \mathrm{D}$ converter at a resolution of 16 bits. For oversampled variables $(100 \mathrm{~Hz})$ the resulting signal is block averaged.

The INS has a latency time for internal calculations of $\approx 4 \mathrm{~ms}$. Yet INS and EIDAS data streams have to be merged to calculate the ambient wind, and later turbulent fluxes. Therefore the resulting time lag between INS and 5HP of $\approx 16 \mathrm{~ms}$ has to be considered. The appropriate time shift of one to two $100 \mathrm{~Hz}$ increments is determined via lagged correlation. During post-processing the $100 \mathrm{~Hz}$ INS data set is then shifted by this increment before block averaging to
$10 \mathrm{~Hz}$. A spike test revealed $\approx 7 \%$ missing values in the wing attitude data, which were filled via linear interpolation. To enable angular averaging or interpolation, heading angles were transformed from polar to Cartesian coordinates.

\section{Wind vector}

Approaches to compute the wind vector from fixed-wing aircraft are often similar in principle, though differ considerably in detail (e.g., Tjernström and Friehe, 1991; Williams and Marcotte, 2000; van den Kroonenberg et al., 2008). Therefore we provide a supplement to this study which can be found here. Supplement A details the specific implementation that was found suitable for the wind measurement with our weight-shift microlight aircraft. A model to propagate uncertainty through the wind vector equations is provided in Supplement B. Relevant notation and abbreviations are listed in Supplement C.

The system's calibration was arranged bottom-up, i.e. from single instrument to collective application. The procedure starts with the laboratory calibration of the individual sensors, continues with the characterization of flow around the 5HP, and concludes with the treatment of WSMA specific effects on the wind measurement. Finally three independent lines of analysis are used to quantify the overall system uncertainty: (a) uncertainty propagation through respective equations, (b) in-flight testing and (c) comparison of the measured wind vector with ground based measurements.

\subsection{Calibration and evaluation layout}

Prior to in-flight use, the five hole probe was tested in an open wind tunnel at the Technical University of Munich, Germany, Institute for Fluid Mechanics. Objectives were to (a) confirm the applicability of transformation Eqs. (A5)-(A7) and (b) determine the 5HP's uncertainty in the operational range of the WSMA. The 5HP was mounted on D-MIFU's nosecap and measuring occurred at airflow velocities ranging 
Table 2. List of measured variables, sensor characteristics, signal processing and data acquisition. Individual sensor locations are described in Sect. 2.2 and displayed in Figs. 1 and 3. Resolution refers to the smallest change registered by the data acquisition (DAQ) units. $\sigma$ is the overall sensor uncertainty provided by the manufacturer in form of one standard deviation. Signal rates are displayed for sampling, filtering and storing (Signal SFS). Data acquisition takes place in two forms, standalone (SA) and on the central DAQ unit EIDAS. For non SA devices signal forwarding via A/D converter, recommended standard 232 (RS232) or serial peripheral interface (SPI) is indicated (Interface DAQ). Continued on next page.

\begin{tabular}{|c|c|c|c|c|c|c|c|c|c|c|}
\hline \multirow[t]{2}{*}{ Quantity } & \multirow[t]{2}{*}{ Variable } & \multirow[t]{2}{*}{ Sensor } & \multirow[t]{2}{*}{ Range } & \multirow{2}{*}{$\begin{array}{l}\text { Resolution } \\
\text { on }\end{array}$} & \multirow[t]{2}{*}{$\sigma$} & \multicolumn{3}{|c|}{ Signal SFS $\left[\mathrm{s}^{-1}\right]$} & \multicolumn{2}{|c|}{ Interface DAQ } \\
\hline & & & & & & & & & & \\
\hline Latitude/longitude & & RT3102 & $\pm 89.9^{\circ} / \pm 180^{\circ}$ & $6 \times 10^{-15 \circ}$ & $1.1 \mathrm{~m}$ & 100 & & 100 & & SA \\
\hline Altitude sea level & & RT3102 & $<18000 \mathrm{~m}$ & $0.001 \mathrm{~m}$ & $2.7 \mathrm{~m}$ & 100 & & 100 & & SA \\
\hline Altitude ground level & & ULS & $0.15-500 \mathrm{~m}$ & $0.001 \mathrm{~m}$ & $0.04 \mathrm{~m}$ & 10 & & 10 & $\mathrm{RS} 232$ & EIDAS \\
\hline Heading, body & $\Psi^{\mathrm{b}}$ & RT3102 & $0-360^{\circ}$ & $0.00006^{\circ}$ & $0.1^{\circ}$ & 100 & & 100 & & SA \\
\hline Heading, wing & $\Psi^{\mathrm{W}}$ & TCM2-20 & $0-360^{\circ}$ & $0.1^{\circ}$ & $0.5^{\circ}$ & 16 & & 10 & RS232 & EIDAS \\
\hline Pitch/roll, body & $\Theta^{\mathrm{b}} / \Phi^{\mathrm{b}}$ & RT3102 & $\pm 90^{\circ} / \pm 180^{\circ}$ & $0.00006^{\circ}$ & $0.06^{\circ}$ & 100 & & 100 & & SA \\
\hline Pitch/roll, wing & $\Theta^{\mathrm{w}} / \Phi^{\mathrm{w}}$ & TCM2-20 & $\pm 20^{\circ}$ & $0.1^{\circ}$ & $0.2^{\circ}$ & 16 & & 10 & $\mathrm{RS} 232$ & EIDAS \\
\hline 3-D velocity, body & $v_{\mathrm{gS}}^{\mathrm{m}}$ & RT3102 & $0-515 \mathrm{~m} \mathrm{~s}^{-1}$ & $0.0001 \mathrm{~m} \mathrm{~s}^{-1}$ & $0.02 \mathrm{~m} \mathrm{~s}^{-1}$ & 100 & & 100 & & SA \\
\hline 3-D ang. rat., body & $\Omega^{\mathrm{b}}$ & RT3102 & $\pm 100^{\circ} \mathrm{s}^{-1}$ & $0.0006^{\circ} \mathrm{s}^{-1}$ & $0.01^{\circ} \mathrm{s}^{-1}$ & 100 & & 100 & & SA \\
\hline 3-D accel., body & $a^{\mathrm{b}}$ & RT3102 & $\pm 10 \mathrm{~g}$ & $0.00001 \mathrm{~g}$ & $0.001 \mathrm{~g}$ & 100 & & 100 & & SA \\
\hline 3-D accel., wing & & ADXL330 & $\pm 3 \mathrm{~g}$ & $0.0003 \mathrm{~g}$ & $0.01 \mathrm{~g}$ & 100 & & 100 & $\mathrm{~A} / \mathrm{D}$ & EIDAS \\
\hline 3-D accel., 5HP & & ADXL330 & $\pm 3 \mathrm{~g}$ & $0.0003 \mathrm{~g}$ & $0.01 \mathrm{~g}$ & 100 & & 100 & $\mathrm{~A} / \mathrm{D}$ & EIDAS \\
\hline \multicolumn{11}{|c|}{ Relative air motion } \\
\hline Static pressure & $p_{\mathrm{s}, \mathrm{A}}$ & SP82AL & $0-1000 \mathrm{hPa}$ & $0.02 \mathrm{hPa}$ & $0.1 \mathrm{hPa}$ & 100 & 20 & 10 & $\mathrm{~A} / \mathrm{D}$ & EIDAS \\
\hline Dynamic pressure & $p_{q, \mathrm{~A}}$ & PCLA12X5D & $\pm 12.5 \mathrm{hPa}$ & $0.0005 \mathrm{hPa}$ & $0.06 \mathrm{hPa}$ & 100 & 20 & 10 & $\mathrm{~A} / \mathrm{D}$ & EIDAS \\
\hline Attack pressure & $p_{\alpha}$ & PCLA12X5D & $\pm 12.5 \mathrm{hPa}$ & $0.0005 \mathrm{hPa}$ & $0.06 \mathrm{hPa}$ & 100 & 20 & 10 & $\mathrm{~A} / \mathrm{D}$ & EIDAS \\
\hline Sideslip pressure & $p_{\beta}$ & PCLA12X5D & $\pm 12.5 \mathrm{hPa}$ & $0.0005 \mathrm{hPa}$ & $0.06 \mathrm{hPa}$ & 100 & 20 & 10 & $\mathrm{~A} / \mathrm{D}$ & EIDAS \\
\hline Fast temp. & $T_{\mathrm{S}}$ & CHAL-002 & $-20-60^{\circ} \mathrm{C}$ & $0.0015 \mathrm{~K}$ & $0.5 \mathrm{~K}$ & 100 & 20 & 10 & $\mathrm{~A} / \mathrm{D}$ & EIDAS \\
\hline Humidity, 5HP & $e^{0}$ & SHT75 & $0-70 \mathrm{hPa}$ & $0.07 \mathrm{hPa}$ & $0.3 \mathrm{hPa}$ & 10 & & 10 & SPI & EIDAS \\
\hline \multicolumn{11}{|c|}{ DAQ synchronization } \\
\hline GPS time & & RT3102 & & $0.001 \mathrm{~s}$ & $0.001 \mathrm{~s}$ & 100 & & 100 & & SA \\
\hline GPS time & & RT3102 & & $0.1 \mathrm{~s}$ & $0.1 \mathrm{~s}$ & 100 & & 10 & $\mathrm{RS} 232$ & EIDAS \\
\hline
\end{tabular}

from 20 to $32 \mathrm{~m} \mathrm{~s}^{-1}$ (equivalent to $2-6 \mathrm{hPa}$ wind tunnel dynamic pressure). The dynamic pressure at the design stagnation point (i.e. the wind tunnel angles of attack $\tilde{\alpha}=0^{\circ}$ and sideslip $\tilde{\beta}=0^{\circ}$ ) was measured at airflow velocity increments of $1 \mathrm{~m} \mathrm{~s}^{-1}$. At increments of $2 \mathrm{~m} \mathrm{~s}^{-1}$ a total of 570 permutations of 10 predefined angles $\tilde{\alpha}$ and $\tilde{\beta}$, each ranging from $0^{\circ}$ to $+20^{\circ}$, were measured. In addition one-dimensional symmetry tests were performed for six predefined angles $\tilde{\alpha}$ and $\tilde{\beta}$ ranging from $-20^{\circ}$ to $+20 \circ$ at an airflow velocity of $30 \mathrm{~m} \mathrm{~s}^{-1}$. For the WSMA operational true airspeed of $28 \mathrm{~m} \mathrm{~s}^{-1}$ (or $4.5 \mathrm{hPa}$ dynamic pressure during flight) the uncertainty of the wind tunnel airflow velocity was $0.7 \%$ or $\sigma=0.03 \mathrm{hPa}$ dynamic pressure. The airflow angles were varied by a calibration robot, the uncertainty in the wind tunnel angles was $\sigma_{\tilde{\alpha}, \tilde{\beta}}<0.1^{\circ}$ (equal to the alignment repeatability between 5HP and INS). The wind tunnel angles $\tilde{\alpha}, \tilde{\beta}$ are related to the airflow angles $\alpha$ and $\beta$ used for the wind calculation (Boiffier, 1998):

$$
\begin{aligned}
& \alpha=\tilde{\alpha}, \\
& \beta=\arctan \left(\frac{\tan \tilde{\beta}}{\cos \tilde{\alpha}}\right) .
\end{aligned}
$$

The wind vector calculated from airborne measurements is very sensitive to uncertainties in its input variables. Calibration in laboratory and assessment in wind tunnel yield the basic sensor setup. However the effect of sensor and alignment uncertainties on the wind vector is not straightforward, and involves numerous trigonometric functions (Supplement A). To make the influence of individual measured quantities on the wind vector transparent, linear uncertainty propagation models were used (Supplement B). The intention is to investigate the wind measurement's uncertainty constraint by sensor setup and wind model description under controlled boundary conditions. Because of flow distortion effects (Sect. 2.1) the boundary conditions during flight however are less well known and might be significantly different from the laboratory. Therefore a methodology for in-flight calibration and evaluation was derived. It consists 
Table 3. Flight campaign summary for locations Lake Starnberg (ST), Lindenberg (LI), and Xilinhot (XI). Anticyclonic and cyclonic conditions are indicated by a and c, respectively. For the flight patterns racetrack (RACE), wind square (SQUA), variance optimization (VARI), vertical wind specific flights (VW1-VW3) and the comparison to ground based measurements (COMP) the number of available datasets for each date is given together with respective track length $(\mathrm{km})$ in parenthesis. Additional information is given in Sect. 3.1 .

\begin{tabular}{|c|c|c|c|c|c|c|c|c|c|c|}
\hline Date & $\begin{array}{l}19 \text { Jun } \\
2008\end{array}$ & $\begin{array}{l}24 \text { Jun } \\
2008\end{array}$ & $\begin{array}{l}25 \text { Jun } \\
2008\end{array}$ & $\begin{array}{l}11 \mathrm{Jul} \\
2008\end{array}$ & $\begin{array}{l}15 \text { Oct } \\
2008\end{array}$ & $\begin{array}{l}16 \text { Oct } \\
2008\end{array}$ & $\begin{array}{l}18 \text { Oct } \\
2008\end{array}$ & $\begin{array}{l}20 \text { Oct } \\
2008\end{array}$ & $\begin{array}{l}21 \mathrm{Oct} \\
2008\end{array}$ & $\begin{array}{l}31 \mathrm{Jul} \\
2009\end{array}$ \\
\hline Location & ST & ST & ST & ST & LI & LI & LI & LI & LI & XI \\
\hline CYC $950 \mathrm{hPa}$ & $\mathrm{a}$ & $\mathrm{a}$ & $\mathrm{c}$ & $\mathrm{c}$ & $\mathrm{a}$ & $\mathrm{c}$ & $\mathrm{a}$ & $\mathrm{a}$ & $\mathrm{c}$ & $\mathrm{a}$ \\
\hline CYC $500 \mathrm{hPa}$ & $\mathrm{a}$ & $\mathrm{a}$ & $\mathrm{a}$ & $\mathrm{a}$ & a & $\mathrm{c}$ & $\mathrm{a}$ & a & $\mathrm{a}$ & $\mathrm{a}$ \\
\hline$p[\mathrm{hPa}]$ & 1019 & 1021 & 1020 & 1015 & 1017 & 1008 & 1020 & 1018 & 1012 & 1010 \\
\hline$T_{\max }\left[{ }^{\circ} \mathrm{C}\right]$ & 22.4 & 21.6 & 27.7 & 27.8 & 14.8 & 14.3 & 13.1 & 16.5 & 21.7 & 31.1 \\
\hline Cloud cover & $5 / 8$ & $4 / 8$ & $4 / 8$ & $4 / 8$ & $8 / 8$ & $8 / 8$ & $5 / 8$ & $4 / 8$ & $4 / 8$ & $7 / 8$ \\
\hline RACE & $2(10)$ & $4(10)$ & $4(10)$ & & & & $4(10)$ & & & \\
\hline SQUA & & $5(12)$ & $1(12)$ & & & & & & & \\
\hline VARI & & & & & & & & $6(20)$ & $4(20)$ & $2(80)$ \\
\hline VW1 & & & $1(4)$ & & & & & & & \\
\hline VW2 & & $1(11)$ & $1(11)$ & & & & & & & \\
\hline VW3 & & & $1(9)$ & & & & & & & \\
\hline COMP & & & & & $6(12)$ & $5(12)$ & $6(12)$ & & & \\
\hline
\end{tabular}

of a WSMA specific calibration model and -flight patterns. These patterns were carried out during three flight campaigns at different sites, each with its characteristic landscape and meteorological forcing:

\subsubsection{Lake Starnberg, Germany}

The first flight campaign took place from 19 June to 11 July 2008 over Lake Starnberg $\left(47.9^{\circ} \mathrm{N}, 11.3^{\circ} \mathrm{E}\right)$. The lake is located in the foreland of the German Alps, that is a slightly rolling landscape (600-800 ma.s.l.) and mainly consists of grassland with patches of forest. The campaign focused on early morning soundings in the free atmosphere above Lake Starnberg.

\subsubsection{Lindenberg, Germany}

In a second campaign from 14-21 October 2008 comparison flights were carried out at the boundary layer measurement field of the German Meteorological Service, Richard-Aßmann-Observatory, near Lindenberg $\left(52.2^{\circ} \mathrm{N}\right.$, $\left.14.1^{\circ} \mathrm{E}\right)$. The area lies in the flat North German Plain (40$100 \mathrm{~m}$ a.s.1.), where land-use in the vicinity is dominated by an equal amount of agriculture and forests, interspersed by lakes. Flights in the atmospheric boundary layer were conducted under near-neutral stratification (stability parameter $\left.\left|\frac{z}{L}\right| \leq 0.2\right)$.

\subsubsection{Xilinhot, China}

To extend the operational range, an additional dataset under conditions approaching free convection $\left(\frac{z}{L} \ll-0.2\right)$ was included in this study: From 23 June to 4 August 2009 an Eddy-Covariance flux campaign was performed over the steppe of the Mongolian Plateau. The hilly investigation area south of the provincial capital Xilinhot, Inner Mongolia, China $\left(43.6^{\circ} \mathrm{N}, 116.7^{\circ} \mathrm{E}, 1000-1400 \mathrm{~m}\right.$ a.s.l.) is covered by semi-arid grassland, intersected by a dune belt.

A summary of all flights as well as an overview of the synoptic weather conditions is provided in Table 3. Synoptic wind direction and cyclonality (CYC) were retrieved from the objective weather type data base of the German Meteorological Service (Bissolli and Dittmann, 2001). The XI flight on 31 July 2009 was supplemented with publicly available data from the US National Centre for Environmental Prediction. Prevailing wind direction throughout all flight days was south-west. Sea level pressure $(p), 2 \mathrm{~m}$ a.g.l. maximum temperature $\left(T_{\max }\right)$ and cloud coverage are $24 \mathrm{~h}$ observations of the closest national meteorological service station on the respective day.

In the following, the strategies of the individual flight patterns at these three sites are categorized in five classes and briefly outlined. The first four of them serve to isolate independent parameters for the flow distortion correction, while the last one is used to compare aircraft to ground based measurements. The patterns are used for the actual calibration and evaluation of the wind measurement in Sect. 4.

\subsubsection{Racetrack pattern}

The first type of flight pattern consists of two legs parallel to the mean wind direction at constant altitude (one pair), one upstream leg (subscript + ) and one downstream leg (subscript -). The legs are suitably aligned with the mean wind when having opposite tracks for identical aircraft settings. 
For any racetrack pair flown at constant true airspeed $\left(v_{\text {tas }}\right)$, the (assumed homogeneous and stationary) mean wind $\left(\overline{\boldsymbol{v}^{\mathrm{m}}}\right)$ cancels out (Leise and Masters, 1993; Williams and Marcotte, 2000):

$$
\begin{aligned}
\overline{\left|\boldsymbol{v}_{\mathrm{gs}}^{\mathrm{m}}\right|} & =\frac{1}{2}\left(\overline{\left|\boldsymbol{v}_{\mathrm{gs},+}^{\mathrm{m}}\right|}+\overline{\left|\boldsymbol{v}_{\mathrm{gs},-}^{\mathrm{m}}\right|}\right) \\
& =\frac{1}{2}\left(\left(\overline{v_{\text {tas },+}}+\overline{\left|\boldsymbol{v}^{\mathrm{m}}\right|}\right)+\left(\overline{v_{\text {tas },-}}-\overline{\left|\boldsymbol{v}^{\mathrm{m}}\right|}\right)\right) \\
& =\overline{v_{\text {tas }}}
\end{aligned}
$$

In this way the INS measured ground speed $\left(\overline{\left|\boldsymbol{v}_{\mathrm{gs}}^{\mathrm{m}}\right|}\right)$ can be used to minimize the difference $\left|\overline{\left|\boldsymbol{v}_{\mathrm{gs}}^{\mathrm{m}}\right|}-\overline{v_{\text {tas }}}\right|$ by iteratively adjusting dynamic pressure in Eq. (A8). This yields an inverse reference for dynamic pressure, which is solely based on INS data. Since the temperature and static pressure sensitivities of Eq. (A8) are two orders of magnitude lower than that of the dynamic pressure (Table 5), the inverse reference can now be used to adjust the 5HP measured dynamic pressure to in-flight conditions. A total of 14 racetrack pairs at airspeeds ranging from 21 to $32 \mathrm{~m} \mathrm{~s}^{-1}$ were conducted in the calm and steady atmosphere above the ABL (Table 3).

\subsubsection{Wind square pattern}

The second type of flight pattern consists of four legs flown at constant altitude and constant $v_{\text {tas }}$ in the cardinal directions (north $(\mathrm{N})$, east $(\mathrm{E})$, south $(\mathrm{S})$, west $(\mathrm{W})$ ). Assuming that the flights were carried out in a homogeneous and stationary wind field, the measured horizontal wind components $\left(v_{u}^{\mathrm{m}}, v_{v}^{\mathrm{m}}\right)$ should be independent of aircraft heading, i.e. constant at each side of the wind square. With it a potential offset in $\beta$ can be determined: The offset in $\beta$ is changed iteratively, until the standard deviation of $v_{u}^{\mathrm{m}}$ and $v_{v}^{\mathrm{m}}$ throughout a wind square is minimized. For flights above the ABL, in addition the vertical wind component can be expected to be negligible. A potential offset in $\alpha$ can be determined in a similar fashion to $\beta$, however, under the constraint of minimizing the absolute value of the vertical wind component $\left(v_{\mathrm{w}}^{\mathrm{m}}\right)$. The wind square pattern further allows to estimate the uncertainties of $v_{\text {tas }}$ and $\beta$ : Since the flight legs are aligned in the cardinal directions, along-track wind components $\left(v_{u}^{\mathrm{m}}(\mathrm{N}, \mathrm{S}), v_{v}^{\mathrm{m}}(\mathrm{E}, \mathrm{W})\right)$ are predominantly sensitive to errors in $v_{\text {tas }}$. Cross-track wind components $\left(v_{v}^{\mathrm{m}}(\mathrm{N}, \mathrm{S})\right.$, $\left.v_{u}^{\mathrm{m}}(\mathrm{E}, \mathrm{W})\right)$ are predominantly sensitive to errors in $\beta$. Thus, errors in $v_{\text {tas }}$ and $\beta$ can be estimated as:

$$
\begin{aligned}
& \sigma_{u v, \text { tas }}=\sqrt{\frac{1}{2}\left(\left(\overline{v_{u}^{\mathrm{m}}}(\mathrm{N})-\overline{v_{u}^{\mathrm{m}}}(\mathrm{S})\right)^{2}+\left(\overline{v_{v}^{\mathrm{m}}}(\mathrm{E})-\overline{v_{v}^{\mathrm{m}}}(\mathrm{W})\right)^{2}\right)} \\
& \sigma_{u v, \beta}=\sqrt{\frac{1}{2}\left(\left(\overline{v_{v}^{\mathrm{m}}}(\mathrm{N})-\overline{v_{v}^{\mathrm{m}}}(\mathrm{S})\right)^{2}+\left(\overline{v_{u}^{\mathrm{m}}}(\mathrm{E})-\overline{v_{u}^{\mathrm{m}}}(\mathrm{W})\right)^{2}\right)} .
\end{aligned}
$$

Six wind squares were flown above the $\mathrm{ABL}$ at airspeeds from 23 to $29 \mathrm{~m} \mathrm{~s}^{-1}$ (Table 3).

\subsubsection{Variance optimization pattern}

The third type of flight pattern is a straight and level ABL sounding, intended for EC flux measurement. The assumption made here is that errors in the flow angles increase the wind variance. In contrast to the previous two patterns, this method does not imply homogeneity or stationarity. It can therefore be applied even in the presence of thermal turbulence, i.e. in the convective ABL (Tjernström and Friehe, 1991; Khelif et al., 1999; Kalogiros and Wang, 2002a). Offsets and slopes for $\alpha$ and $\beta$ were computed to minimize (a) the sum of the wind components variances plus (b) the absolute value of the mean vertical wind. Here it is expected that, for a sufficiently high number of datasets above approximately level terrain, $\overline{v_{w}^{m}}$ approaches zero. 12 straight and level ABL soundings (or $360 \mathrm{~km}$ of flight data, Table 3) at airspeeds from 24 to $28 \mathrm{~m} \mathrm{~s}^{-1}$ between 50 and $160 \mathrm{~m}$ above ground were used for this variance optimization.

\subsubsection{Vertical wind specific patterns}

The fourth type of flight pattern specifically addresses errors in $v_{w}^{\mathrm{m}}$, the wind component crucial for EC flux applications. Based on Lenschow (1986) straight-flight calibration patterns were performed above the ABL. These are intended to assess and minimize the possible influence of aircraft (in our case WSMA) trim and dynamics on $v_{w}^{\mathrm{m}}$. At airspeeds ranging from 21 to $32 \mathrm{~m} \mathrm{~s}^{-1}$ a total of five vertical wind (VW) specific flights, divided into three sub-patterns, were utilized in this study (Table 3):

- VW1 - (Level acceleration - deceleration): whilst the engine's power setting was gradually varied, the wing pitch (and with it lift coefficient) was adjusted to maintain flight altitude. With this pattern the influence of aircraft trim on $v_{w}^{\mathrm{m}}$ can be determined.

- VW2 - (Smooth oscillation): starting from level flight the power setting was slowly varied, while the wing pitch was adjusted to maintain constant $v_{\text {tas }}$. In consequence, the aircraft ascended and descended about the mean height, while $C L$ remained approximately unchanged. VW2 was used to assess the influence of wing pitch and aircraft vertical velocity on $v_{w}^{\mathrm{m}}$.

- VW3 - (Forced oscillation): starting from level flight the wing pitch was forcibly alternated. The aircraft ascended and descended around the mean height, while power setting remained unchanged. In response aircraft accelerations and velocities, and with it the airflow around the aircraft, changed. VW3 was used to assess the integral influence of vertically accelerated flight on $v_{w}^{\mathrm{m}}$, as e.g. during terrain following flights in the ABL (see Sect. 4.1, Step G6). 


\subsubsection{Comparison to ground based reference measurements}

The fifth and last type of flight pattern is a series of comparison measurements between WSMA and ground based measurements. These were carried out at the boundary layer measurement field of the German Meteorological Service, Richard-Aßmann-Observatory, near Lindenberg. The lower part of the ABL was probed by a 99-m tower and a SODAR with their base at $73 \mathrm{~m}$ a.s.l. The $99-\mathrm{m}$ tower provided cup measurements (10 min averages) of wind speed at four levels (40, 60, 80, and $98 \mathrm{~m}$ a.g.l.), the wind direction was measured with vanes at heights of 40 and $98 \mathrm{~m}$ a.g.1. (10 min averages). Sonic anemometers mounted at the tower provided turbulent wind vector measurements at 50 and $90 \mathrm{~m}$ a.g.l. The SODAR wind vector profiles ( $15 \mathrm{~min}$ averages) reached, at increments of $20 \mathrm{~m}$, from 40 to $240 \mathrm{~m}$ a.g.l. In addition a reference for static pressure was provided at $1 \mathrm{~m}$ a.g.l. 17 cross-shaped patterns (van den Kroonenberg et al., 2008), with flight legs of $3 \mathrm{~km}$ centred between tower and SODAR, were performed at 24 and $27 \mathrm{~m} \mathrm{~s}^{-1}$ airspeed (Table 3). The flights were carried out at the approximate sounding levels of tower and SODAR (50, 100, 150, 200 and $250 \mathrm{~m}$ a.g.1.). This allows a direct comparison of WSMA and ground based measured wind components. Aircraft and sonic wind measurements were filtered using the stationarity test for wind measurements by Foken and Wichura (1996). SODAR, cup and vane data were stratified for the best quality rating assigned by the German Meteorological Service. Simultaneous wind data of WSMA and ground based measurements were accepted for comparison only if they agreed to within $\pm 20 \mathrm{~m}$ height above ground (which equals $\approx 2 \sigma$ of variations in WSMA altitude). This data screening resulted in a total of 20 data couples (between WSMA and cups/vanes, sonics and SODAR) for $v_{u v}^{\mathrm{m}}$, and 19 data couples for $v_{w}^{\mathrm{m}}$. Compared to cups/vanes, sonics and SODAR, the WSMA soundings were on average higher above ground by $0.1 \pm 5.5,8.7 \pm 5.6$, and $0.5 \pm 5.3 \mathrm{~m}$, respectively.

\section{Application to weight-shift microlight aircraft}

To understand operational requirements for setup and calibration of the wind vector measurement, aircraft attitude and dynamics were assessed for a straight and level boundary layer flight (Table 3, variance optimization flight on 31 July 2009). Histograms of aircraft properties were calculated from $\approx 3 \times 10^{4}$ data points sampled $\approx 50$ m a.g.l. (Fig. 4). Variations in true airspeed and aircraft vertical movement were resulting from aircraft manoeuvres to follow the terrain contours as well as thermal turbulence (labile stratification, stability parameter $\frac{z}{L} \approx-0.9$ ). Attitude angles $\left(\Theta^{\mathrm{b}}, \Phi^{\mathrm{b}}\right)$ indicate constant upward pitching and anticlockwise roll of the trike, respectively. Pitching as well as rolling increase in magnitude with $v_{\text {tas }}$, i.e. power setting of the engine. The pitching moment can be understood as a result of imbalanced increase of aerodynamic resistance of wing (high) and trike (low) with $v_{\text {tas }}$. This is confirmed by an estimate of the attack angle $(\alpha)$, which shows fewer variation due to alignment with the streamlines, though alike $\Theta^{\mathrm{b}}$ increases with $v_{\text {tas }}\left(\approx 0.4^{\circ}\right.$ per $\left.\mathrm{m} \mathrm{s}^{-1}\right)$. The rolling moment can be understood as counter-balance of the clockwise rotating propeller torque. In addition side-slipping of the trike over its port side was detected from an estimate of the sideslip angle $(\beta)$, increasing at a rate of $\approx-0.6^{\circ}$ per $\mathrm{m} \mathrm{s}^{-1}$ with $v_{\text {tas. }}$. The operational range in $\alpha$ and $\beta$ estimates were found $\approx\left|15^{\circ}\right|$, averaging to $6.0 \pm 1.8^{\circ}$ and $-5.5 \pm 3.2^{\circ}$, respectively (Fig. 4). Following the lift Eq. (2), wing pitch decreases with $v_{\text {tas }}$. That is, with increasing $v_{\text {tas }}$ the noses of wing and trike approach each other. Wing roll does not display dependence on $v_{\text {tas }}$, i.e. no counter reaction on propeller torque or trike roll. The wing loading factor (LF) was found to vary within a range of $\sigma \approx 0.1 \mathrm{~g}$ (Fig. 4), from which the upwash variation in front of the wing can be assessed.

Using five hole probe measured $v_{\text {tas }}$ in Eq. (3) the upwash velocity $\left(v_{\text {up }}^{w}\right)$ at $5 \mathrm{HP}$ location was determined to $1.52 \pm 0.19 \mathrm{~m} \mathrm{~s}^{-1}$. D-MIFU is travelling at low airspeed and has a small relative separation $(n)$ between wing and 5HP. Both factors lead to an increase in $v_{\text {up }}^{w}$. Various research aircraft have been assessed with regard to upwash generation (Crawford et al., 1996), compared to which D-MIFU ranges mid-table. This can be ascribed to the low wing loading, which is a fraction of those of fixed-wing aircraft, and decreases $v_{\mathrm{up}}^{w}$. Wing loading, and with it $v_{\mathrm{up}}^{w}$, are directly proportional to vertical acceleration and aircraft mass in Eq. (1). Hence $\sigma \approx 10 \%$ variation in LF (Fig. 4) accounts for most of the variance in $v_{\text {up }}^{w}$. In addition aircraft mass can vary during the flight due to fuel consumption $( \pm 4 \%)$ and among measurements due to weight differences of pilots $( \pm 2 \%)$. Due to the trike's rotational freedom, upwash about the wing's centre of pressure can partially translate into along- and sidewash (longitudinal and transverse to the trike body, respectively) at the 5HP location in the trike body coordinate system (BCS). Mean aerodynamic chord theory yields the centre of pressure's position of the wing within $0.2 \mathrm{~m}$ or $<10 \%$ chord length of the centre of gravity. Assuming the centres of pressure and gravity to coincide, the pitch difference between wing and trike can be neglected, and $v_{\mathrm{up}}^{w}$ is easily transformed into the BCS: the transformation Eq. (A13) was carried out about zero heading difference, the wing upwash direction $\left(\xi=-41.9 \pm 0.3^{\circ}\right)$, and the roll difference between wing and trike. Wing upwash net effect at the 5HP location was then directed forward, right and upward with $1.01 \pm 0.13 \mathrm{~m} \mathrm{~s}^{-1}$, $0.12 \pm 0.13 \mathrm{~m} \mathrm{~s}^{-1}$, and $-1.12 \pm 0.14 \mathrm{~m} \mathrm{~s}^{-1}$ in trike body coordinates (Fig. 5).

\subsection{Wind measurement calibration}

The sensitivity of the wind model description was analysed by linear uncertainty propagation models (Supplement B). 

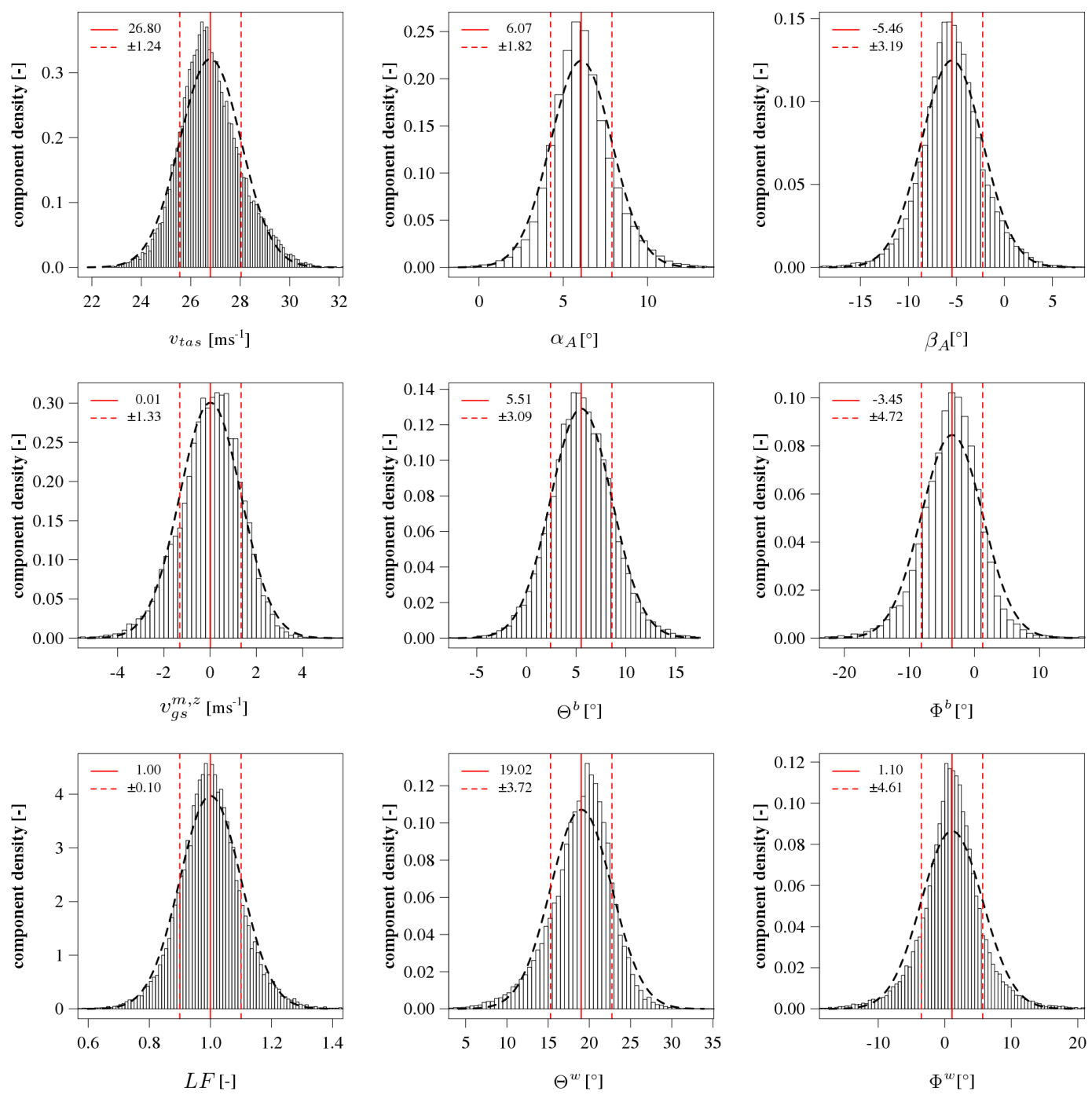

Fig. 4. Histograms of aircraft properties derived for the flight on 31 July 2009 (Table 3). Component density is scaled so that the histograms have a total area of one. Red vertical lines indicate distribution average (solid) and standard deviation (dashed). The black dashed bell curve displays a reference normal distribution: True airspeed $\left(v_{\text {tas }}\right)$, attack angle $\left(\alpha_{\mathrm{A}}\right)$, sideslip angle $\left(\beta_{\mathrm{A}}\right)$, aircraft vertical velocity $\left(v_{\mathrm{gs}}^{\mathrm{m}, z}\right)$, trike pitch- $\left(\Theta^{\mathrm{b}}\right)$ and roll $\left(\Phi^{\mathrm{b}}\right)$ angles, loading factor (LF, the ratio of lift- to weight force), as well as wing pitch- $\left(\Theta^{\mathrm{w}}\right)$ and roll $\left(\Phi^{\mathrm{W}}\right)$ angles.

The first model in Eq. (B1) permits to express the sensitivity of the wind computation as a function of attitude angles, flow angles and true airspeed. It was carried out for two reference flight states at $v_{\text {tas }}=27 \mathrm{~m} \mathrm{~s}^{-1}$. In State 1 attitude and flow angles were assumed small $\left(1^{\circ}\right)$, as it would be typical for calm atmospheric conditions. This allows for the small-angle approximation in Eq. (B1), resulting in uncertainties for the wind components $\left(\Delta v_{u v w}^{\mathrm{m}}\right)$ as a function of the heading angle $(\Psi)$. In State 2 attitude $\left(10^{\circ}\right)$ and flow angles $\left(-15^{\circ}\right)$ were approximately increased to their $95 \%$ confidence intervals during soundings in the convective $\mathrm{ABL}$ (Fig. 4). Uncertainties of $1^{\circ}$ and $0.5 \mathrm{~m} \mathrm{~s}^{-1}$ were assumed for angular- and $v_{\text {tas }}$ measurements, respectively. Consequently the full form of Eq. (B1) must be used for State 2. It allows to calculate the maximum uncertainty in the wind components $\left(\left|\Delta v_{u v w}^{\mathrm{m}}\right|\right)$ over all $\Psi$, as well as to compare these between both flight states. From State 1 it can be seen that the major uncertainty in the horizontal wind components $\left(v_{u v}^{\mathrm{m}}\right)$ originates from $v_{\text {tas }}$, sideslip angle $(\beta)$ and heading angle $(\Psi)$, where $\beta$ and $\Psi$ carry similar sign and sensitivity (Table 4$)$. On the contrary, the vertical wind component $\left(v_{w}^{\mathrm{m}}\right)$ is similarly sensitive to attack angle $(\alpha)$ and pitch angle $(\Theta)$, yet with reversed sign. As compared to State 1, in State 2 the absolute uncertainties in the horizontal $\left(\left|\Delta v_{u v}^{\mathrm{m}}\right|\right)$ and vertical $\left(\left|\Delta v_{w}^{\mathrm{m}}\right|\right)$ wind components are increased by $24 \%$ and $18 \%$, respectively. The increase however does not originate from the most sensitive-, but from formerly negligible terms such as trike roll $\left(\Phi^{\mathrm{b}}\right)$. The latter now account for 

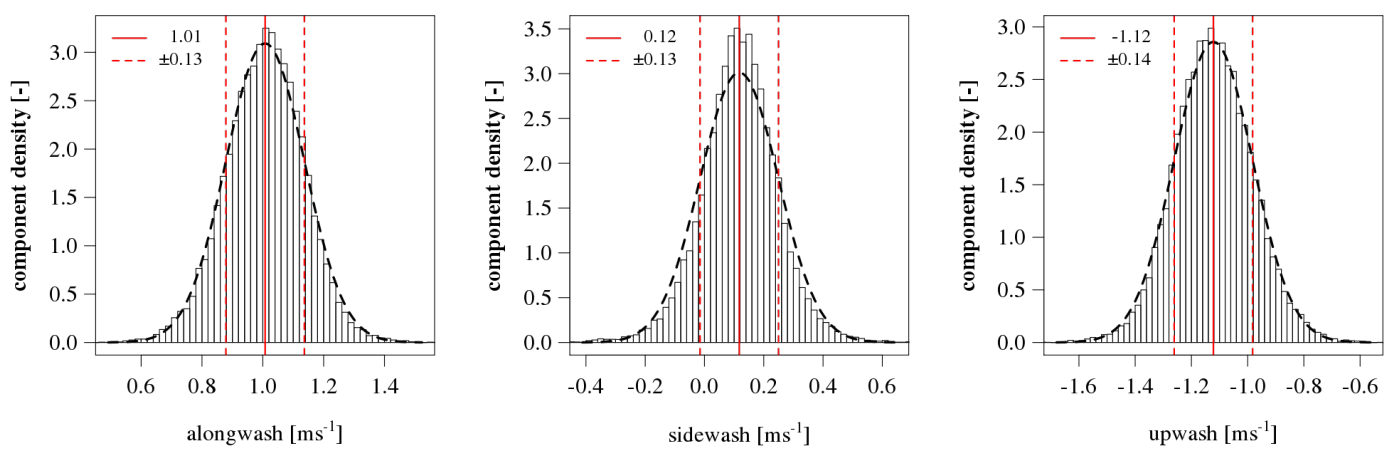

Fig. 5. Histograms of wing-generated alongwash, sidewash and upwash at the five hole probe location. Results are calculated from wing properties in Eqs. (1)-(3) and then rotated from wing- into trike body coordinates (Fig. 2) using Eq. (A13). Presented is the same dataset and in the same manner as in Fig. 4.

up to $50 \%$ of $\left|\Delta v_{u v}^{\mathrm{m}}\right|$ and $37 \%$ of $\left|\Delta v_{w}^{\mathrm{m}}\right|$. In Table 5 similar sensitivity analyses were carried out for $\alpha$ in Eq. (A5), $\beta$ in Eq. (A6) and the thermodynamic derivation of $v_{\text {tas }}$ in Eq. (A8). The input uncertainties were Gaussian summarized $\left(\sigma_{\mathrm{gau}, i}\right)$ and propagated into output uncertainties $(\sigma)$ of attack angle $(\alpha)$, sideslip angle $(\beta)$ and true airspeed $\left(v_{\text {tas }}\right)$, using the sensitivities $(S)$ in their respective computations Eqs. (A5), (A6), and (A8). Propagated output uncertainties were summed up in analogy to Eq. (B1) before Gaussian summarizing them with the non-propagated uncertainties for $\alpha$ and $\beta$ wind tunnel measurements to the final output uncertainties $\left(\sigma_{\text {gau,o }}\right)$. Also here $v_{\text {tas }}=27 \mathrm{~m} \mathrm{~s}^{-1}$ was assumed as reference state, parametrized as $3.7 \mathrm{hPa}$ dynamic pressure $\left(p_{q}\right), 21^{\circ} \mathrm{C}$ static temperature, $850 \mathrm{hPa}$ static pressure, and $9.5 \mathrm{hPa}$ water vapour pressure. Derived sensitivities indicate a dominant dependence of $\alpha$ and $\beta$ on their respective differential pressure measurement, as well as on $p_{q}$. In case of $v_{\text {tas }}$ sensitivity on the $p_{q}$ measurement clearly prevails. This procedure allows to separate, and consequently further concentrate on, the variables most sensitive to the wind vector calculation. For $v_{w}^{\mathrm{m}}$, the central wind component in the Eddy-Covariance flux technique, the variables to focus calibration effort on are $\alpha, \Theta$ and $p_{q}$. Likewise correct readings of $\beta, p_{q}$ and $\Psi$ are of greatest importance for the calculation of $v_{u v}^{\mathrm{m}}$.

Due to the same adiabatic heating effect (ram rise) as in Eq. (A9), the temperature measured by the thermocouple might be slightly higher than the static temperature intrinsic to the air. At the same time the measured temperature is smaller than the total temperature at the stagnation point on the tip of the 5HP, since the air at the thermocouple is not brought to rest. Even at peak $v_{\text {tas }}=30 \mathrm{~m} \mathrm{~s}^{-1}$ of the WSMA the ram rise of $0.4 \mathrm{~K}$ does not surpass the overall uncertainty of the thermocouple (Table 2). As a practical advantage of the slow flying WSMA therefore no fractional "recovery factor" correction as known from faster fixed-wing aircraft needs to be introduced (Trenkle and Reinhardt, 1973). Using above sensitivity analysis the associated uncertainty amounts to $0.02 \mathrm{~m} \mathrm{~s}^{-1}$ in $v_{\text {tas. }}$. According to the parametrizations (5) and (7) in Foken (1979) the error caused by solar radiation intermittently incident at the unshielded thermocouple was estimated to be $<0.05 \mathrm{~K}$. Since no radiation shielding was applied, both temperature errors were included in the uncertainty propagation (Table 5).

The actual calibration sequence was organized in seven steps (Fig. 6), resulting in an incrementally refined system. To reduce scatter and facilitate convergence of the iterative process the $10 \mathrm{~Hz}$ aircraft data were block averaged to $1 \mathrm{~Hz}$ for steps $D-G$ :

Step A - Laboratory: Initial calibration of all A/D devices. Step B - Wind tunnel: Assessment of attack- $(\alpha)$ and sideslip angle $(\beta)$ and first correction of dynamic pressure $\left(p_{q}\right)$.

Step C - Tower fly-bys: Adjustment of static pressure $\left(p_{\mathrm{s}}\right)$. Step D - Racetracks: Second $p_{q}$ correction.

Step E - Wind squares: First estimate of $\alpha$ and $\beta$ correction. Step F - Variance optimization: Second estimate of $\alpha$ and $\beta$ correction.

Step G - Vertical wind treatment: Relation of measured net flow distortion to lift coefficient, iterative optimization with steps E-F.

\subsubsection{Step A - laboratory}

Calibration coefficients from laboratory and all successive steps are summarized in Table 6. Residuals are propagated together with sensor uncertainties as provided by the manufacturers. The resulting uncertainties are summarized in Table 5.

\subsubsection{Step B - wind tunnel}

Since the wind tunnel was too small for the complete aircraft, the setup was reduced to the five hole probe and the aircraft's nose-cap. Therefore the actual flow distortion during flight was not included in this step. For angles of attack 


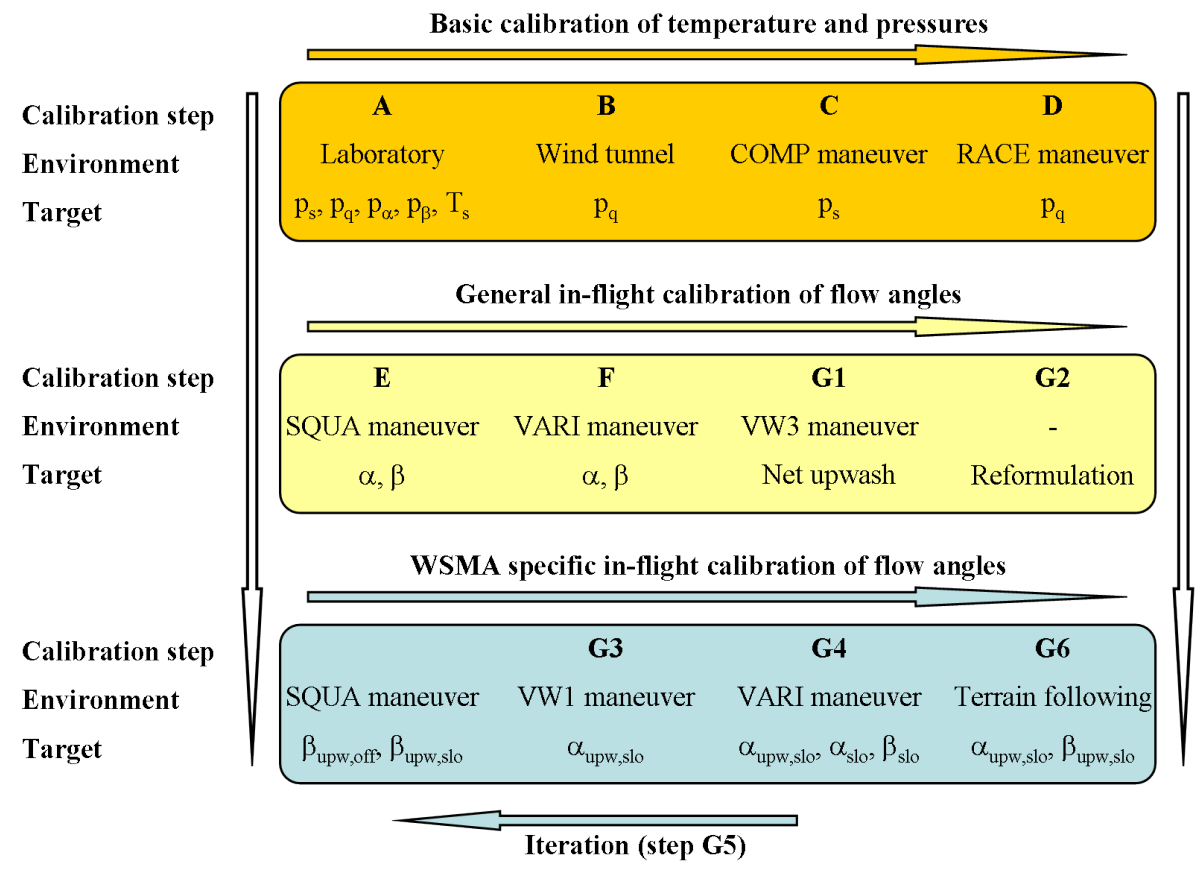

Fig. 6. Flow chart of the calibration process. The calibration steps A-G are carried out in a sequence from left to right, top to bottom. Each step results in an incrementally refined system. The iterative step G5 (blue background) comprises the three flight manoeuvres SQUA, VW1 and VARI. Within G5 the SQUA manoeuvre is not associated with an individual calibration step.
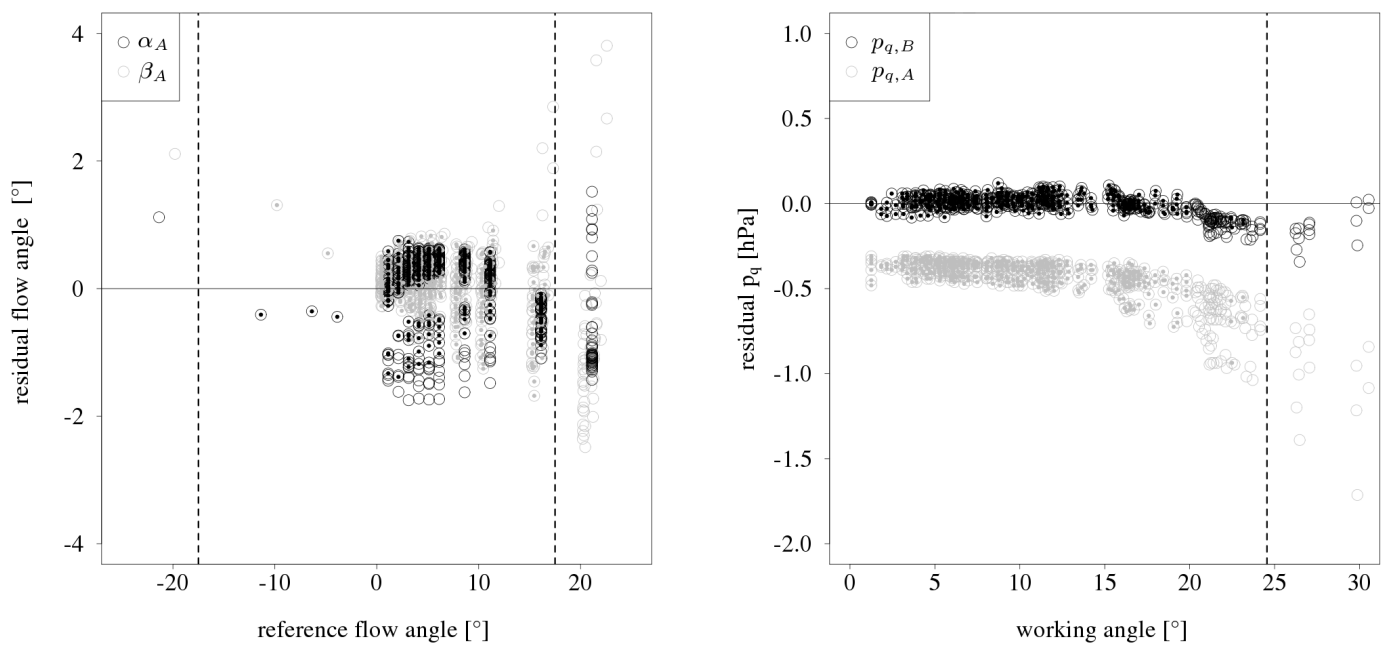

Fig. 7. Wind tunnel evaluation results: open circles represent the residuals for all combinations of flow angles $\left(\alpha_{\mathrm{A}}, \beta_{\mathrm{A}}\right.$, left) and dynamic pressure before $\left(p_{q, \mathrm{~A}}\right)$ and after $\left(p_{q, \mathrm{~B}}\right)$ wind tunnel correction (right). Full circles indicate subsets that lie in the (extended) operational flow angle range of $\pm 17.5^{\circ}$. These subsets are used for the uncertainty assessment. Dashed vertical lines indicate the corresponding thresholds of flow angle and working angle $(\operatorname{acos}(\cos \alpha \cos \beta))$, respectively.

$(\alpha)$ and sideslip $(\beta)$ within $\pm 17.5^{\circ}$ the first-order approximations Eqs. (A5)-(A6) were most effective for deriving flow angles from our miniaturized 5HP. Root mean square error (RMSE) and bias (BIAS) amounted to $0.441,0.144^{\circ}$ and $0.428,0.047^{\circ}$ for $\alpha$ and $\beta$, respectively, with a Pearson Coefficient of determination $R^{2}>0.99$. Residuals did not scale with true airspeed, but resulted from incomplete removal of $\alpha$ and $\beta$ cross dependence (Fig. 7). The probe design was working less reliably with the exact solutions for flow angle determination (e.g. Eq. 7 in Crawford and Dobosy, 1992). We speculate that this behaviour arises from the amplified pressure drops in the attack and sideslip differential pressures $\left(p_{\alpha, \beta}\right)$ at elevated angles. In contrast to their $1.5 \mathrm{~mm}$ pressure ports, the dynamic pressure ( $p_{q, \mathrm{~A}}$, subscript 
Table 4. Input uncertainty (IU) from the linear uncertainty propagation model Eq. (B1). For the sensitivity analysis the model was forced with two different reference states, State 1 with small and State 2 with enhanced flow $(\alpha, \beta)$ and attitude $\left(\Theta^{\mathrm{b}}, \Phi^{\mathrm{b}}, \Psi^{\mathrm{b}}\right.$,) angles. Both states were inferred similar uncertainty quantities $\Delta f_{i}$ in $\alpha, \beta, \Theta^{\mathrm{b}}, \Phi^{\mathrm{b}}, \Psi^{\mathrm{b}}$, and true airspeed $\left(v_{\text {tas }}\right)$. After calibration step B the reference State 2 was used for the uncertainty propagation: the actual uncertainties in (a) the flow computation ( $\alpha, \beta$ and $v_{\text {tas }}$, Table 5), and (b) the sensor alignment $\left(\Theta^{\mathrm{b}}, \Phi^{\mathrm{b}}, \Psi^{\mathrm{b}}\right)$ were inferred. Additional information is given in Sect. 4.1.

\begin{tabular}{|c|c|c|c|c|c|c|c|}
\hline Variable & $\alpha$ & $\beta$ & $\Theta^{\mathrm{b}}$ & $\Phi^{\mathrm{b}}$ & $\Psi^{\mathrm{b}}$ & $v_{\text {tas }}$ & IU \\
\hline \multicolumn{8}{|c|}{ Model forcing } \\
\hline State 1 & $1^{\circ}$ & $1^{\circ}$ & $1^{\circ}$ & $1^{\circ}$ & $0 \ldots 360^{\circ}$ & $27 \mathrm{~m} \mathrm{~s}^{-1}$ & \\
\hline State 2 & $-15^{\circ}$ & $-15^{\circ}$ & $10^{\circ}$ & $10^{\circ}$ & $0 \ldots 360^{\circ}$ & $27 \mathrm{~m} \mathrm{~s}^{-1}$ & \\
\hline$\Delta f_{i, \text { sensitivity }}$ & $1^{\circ}$ & $1^{\circ}$ & $1^{\circ}$ & $1^{\circ}$ & $1^{\circ}$ & $0.5 \mathrm{~m} \mathrm{~s}^{-1}$ & \\
\hline$\Delta f_{i, \text { propagation }}$ & $0.76^{\circ}$ & $0.76^{\circ}$ & $0.1^{\circ}$ & $0.1^{\circ}$ & $0.1^{\circ}$ & $0.34 \mathrm{~m} \mathrm{~s}^{-1}$ & \\
\hline \multicolumn{8}{|c|}{ Results State $1-$ sensitivity } \\
\hline$\Delta v_{u}^{\mathrm{m}}\left[\mathrm{m} \mathrm{s}^{-1}\right]$ & $<0.01$ & $0.47 \cos \Psi$ & $<0.01$ & $<0.01$ & $0.47 \cos \Psi$ & 0.50 & 1.08 \\
\hline$\Delta v_{v}^{\mathrm{m}}\left[\mathrm{m} \mathrm{s}^{-1}\right]$ & $<0.01$ & $-0.47 \sin \Psi$ & $<0.01$ & $<0.01$ & $-0.47 \sin \Psi$ & 0.50 & 1.08 \\
\hline$\Delta v_{w}^{\mathrm{m}}\left[\mathrm{m} \mathrm{s}^{-1}\right]$ & 0.47 & $<0.01$ & -0.47 & $<0.01$ & $<0.01$ & $<0.01$ & 0.95 \\
\hline$\left|\Delta v_{u v}^{\mathrm{m}}\right|\left[\mathrm{m} \mathrm{s}^{-1}\right]$ & 0.01 & 0.47 & $<0.01$ & 0.01 & 0.47 & 0.5 & 1.08 \\
\hline$\left|\Delta v_{w}^{\mathrm{m}}\right|\left[\mathrm{m} \mathrm{s}^{-1}\right]$ & 0.47 & 0.01 & 0.48 & 0.01 & 0.00 & $<0.01$ & 0.97 \\
\hline \multicolumn{8}{|c|}{ Results State $2-$ sensitivity } \\
\hline$\left|\Delta v_{u v}^{\mathrm{m}}\right|\left[\mathrm{m} \mathrm{s}^{-1}\right]$ & 0.21 & 0.47 & 0.21 & 0.14 & 0.42 & 0.45 & 1.34 \\
\hline$\left|\Delta v_{w}^{\mathrm{m}}\right|\left[\mathrm{m} \mathrm{s}^{-1}\right]$ & 0.41 & 0.05 & 0.32 & 0.14 & 0.00 & 0.22 & 1.14 \\
\hline \multicolumn{8}{|c|}{ Results State 2 - propagation } \\
\hline$\left|\Delta v_{v}^{\mathrm{m}}\right|\left[\mathrm{m} \mathrm{s}^{-1}\right]$ & 0.16 & 0.36 & 0.02 & 0.01 & 0.04 & 0.30 & 0.64 \\
\hline$\left|\Delta v_{w}^{\mathrm{m}}\right|\left[\mathrm{m} \mathrm{s}^{-1}\right]$ & 0.31 & 0.04 & 0.03 & 0.01 & 0.00 & 0.15 & 0.55 \\
\hline
\end{tabular}

upper-case letters A-G indicating calibration stage) is measured against a direction-independent static pressure port (Fig. 3). While allowing for slightly more scatter due to angular cross-dependency, the approximate Eqs. (A5) and (A6) compensate the different pressure drops in the quotient $\frac{p_{\alpha, \beta}}{p_{q, \mathrm{~A}}}$. On the other hand use of a calibration polynomial as suggested by Bohn and Simon (1975) has the advantage that it does not assume rotational symmetry. A fit of the calibration polynomial yielded high precision, however did not prove robust for in-flight use and was discarded. For dynamic pressure $\left(p_{q, \mathrm{~A}}\right)$, offset $(0.22 \mathrm{hPa})$ and slope $(1.05)$ were corrected from zero working angle $(\operatorname{acos}(\cos \alpha \cos \beta))$ measurements. Applying the pressure drop correction Eq. (A7) thereafter reduced the scatter significantly, in particular for elevated working angles (Fig. 7). Below $20^{\circ}$ working angle $\left(\approx 15^{\circ}\right.$ flow angle) $p_{q \text {, B was slightly overestimated, above this a loss }}$ of only $\approx-0.1 \mathrm{hPa}$ remained. RMSE and BIAS amounted to 0.042 and $0.012 \mathrm{hPa}$, respectively, with $R^{2}=0.999$. The wind tunnel study proofs the applicability of the spherical model, Eqs. (A5)-(A7), to determine flow angles and dynamic pressure from our 5HP: the deviations are well within the effects of sensor accuracies, i.e. $0.6^{\circ}$ and $0.06 \mathrm{hPa}$, respectively (Table 5). Consequently in-flight tests with similar scope were omitted.

\subsubsection{Step C - tower fly-bys}

A wing induces lift by generating lower pressure atop and higher pressure below the airfoil. Since the five hole probe is measuring at a position being located below the wing, the static pressure $\left(p_{\mathrm{s}}\right)$ measurement is potentially biased. An offset adjustment was estimated to $-2.26 \pm 0.43 \mathrm{hPa}$ from comparison with tower based measurements (Table 6). No dependence of the adjustment on true airspeed, i.e. propeller slipstream or lift coefficient, could be detected. This can most probably be attributed to the small $v_{\text {tas }}$ range of the WSMA. The dynamic pressure $\left(p_{q}\right)$ is measured using a differential pressure sensor between the static- and total pressure ports (Fig. 3). These ports are located only $165 \mathrm{~mm}$ apart from each other, and are therefore subject to the same position error. Consequently position error cancels out in the $p_{q}$ measurement. 
Table 5. Uncertainty of variables entering the wind vector computation Eq. (A1): Static pressure $\left(p_{\mathrm{S}}\right)$, dynamic pressure as used in the computation of flow angles $\left(p_{q, \mathrm{~A}}\right)$ and the true airspeed $\left(p_{q, \mathrm{~B}}\right)$, differential pressures $\left(p_{\alpha}, p_{\beta}\right)$, static temperature $\left(T_{\mathrm{S}}\right)$ and water vapour pressure $(e)$. Sources of uncertainty $(\sigma)$ are subscripted as follows: manufacturer provided sensor uncertainty (sen), calibration in laboratory (lab), wind tunnel (tun), and wind model description (mod). The $0.05 \mathrm{~K}$ and $0.36 \mathrm{~K}$ uncertainties for radiation and ram rise errors in static temperature $\left(T_{\mathrm{S}}\right)$ were accounted in $\sigma_{\text {mod }}$. Additional information is given in Sect. 4.1.

\begin{tabular}{|c|c|c|c|c|c|c|c|c|c|c|c|c|}
\hline \multicolumn{2}{|c|}{ Variable } & \multicolumn{5}{|c|}{ Input } & \multicolumn{3}{|c|}{ Sensitivities } & \multicolumn{3}{|c|}{ Output } \\
\hline & $\begin{array}{l}\text { Unit } \\
x\end{array}$ & $\begin{array}{c}\sigma_{\mathrm{sen}} \\
{[x]}\end{array}$ & $\begin{array}{l}\sigma_{\text {lab }} \\
{[x]}\end{array}$ & $\begin{array}{c}\sigma_{\text {tun }} \\
{[x]}\end{array}$ & $\begin{array}{c}\sigma_{\text {mod }} \\
{[x]}\end{array}$ & $\begin{array}{c}\sigma_{\mathrm{gau}, i} \\
{[x]}\end{array}$ & $\begin{array}{c}S_{\alpha} \\
{[\% / x]}\end{array}$ & $\begin{array}{c}S_{\beta} \\
{[\% / x]}\end{array}$ & $\begin{array}{c}S_{v_{\text {tas }}} \\
{\left[\mathrm{m} \mathrm{s}^{-2} / x\right]}\end{array}$ & $\begin{array}{l}\sigma_{\alpha} \\
{\left[{ }^{\circ}\right]}\end{array}$ & $\begin{array}{l}\sigma_{\beta} \\
{\left[{ }^{\circ}\right]}\end{array}$ & $\begin{array}{c}\sigma_{v_{\text {tas }}} \\
{\left[\mathrm{m} \mathrm{s}^{-1}\right]}\end{array}$ \\
\hline \multicolumn{13}{|c|}{ Propagated } \\
\hline$p_{\mathrm{s}}$ & {$[\mathrm{hPa}]$} & 0.10 & 0.58 & & & 0.59 & & & -0.01 & & & 0.01 \\
\hline$p_{q, \mathrm{~A}}$ & {$[\mathrm{hPa}]$} & 0.06 & 0.03 & & & 0.07 & 4.26 & 3.60 & & 0.29 & 0.24 & \\
\hline$p_{q, \mathrm{~B}}$ & {$[\mathrm{hPa}]$} & 0.06 & 0.03 & 0.04 & & 0.08 & & & 3.85 & & & 0.30 \\
\hline$p_{\alpha}$ & {$[\mathrm{hPa}]$} & 0.06 & 0.03 & & & 0.07 & 4.57 & 0.97 & & 0.31 & 0.07 & \\
\hline$p_{\beta}$ & {$[\mathrm{hPa}]$} & 0.06 & 0.03 & & & 0.07 & 0.48 & 4.74 & & 0.03 & 0.32 & \\
\hline$T_{\mathrm{S}}$ & {$[\mathrm{K}]$} & 0.26 & 0.40 & & 0.36 & 0.60 & & & 0.04 & & & 0.02 \\
\hline$e$ & {$[\mathrm{hPa}]$} & 0.30 & & & & 0.30 & & & 0.01 & & & \\
\hline$\sum$ & & & & & & & & & & 0.62 & 0.62 & 0.34 \\
\hline \multicolumn{13}{|c|}{ Non-propagated } \\
\hline$\alpha$ & {$\left[{ }^{\circ}\right]$} & & & 0.44 & & 0.44 & 1.00 & & & 0.44 & & - \\
\hline$\beta$ & {$\left[{ }^{\circ}\right]$} & & & 0.43 & & 0.43 & & 1.00 & & & 0.43 & - \\
\hline$\sigma_{\text {gau }, \mathrm{o}}$ & & & & & & & & & & 0.76 & 0.76 & 0.34 \\
\hline
\end{tabular}

\subsubsection{Step D - racetracks}

For racetrack and wind square flights, inhomogeneous flight legs were discarded using the stationarity test for wind measurements by Foken and Wichura (1996). Respective optimality criteria Eqs. (5)-(6) were applied to $1 \mathrm{~Hz}$ block averages of the remaining legs. The dynamic pressure inverse reference from racetracks suggests an offset $(0.213 \mathrm{hPa})$ and slope (1.085) correction. Without considering additional dependences, the fit for different power settings is well determined with $0.115 \mathrm{hPa}$ residual standard deviation and $R^{2}=0.974$. We have seen that the wing upwash $\left(v_{\text {up }}^{w}\right)$ in front of the wing of the WSMA is effective forward, right and upward (Fig. 5), while the propeller slipstream is directed backward and upward at the 5HP location in body coordinate system. As net effect we find that the magnitude of dynamic pressure $\left(p_{q, \mathrm{~B}}\right)$ measured at the 5HP tip, and with it the calculated true airspeed, is reduced. The slope correction from racetracks was used to account for this loss in $p_{q, \mathrm{~B}}$. The suggested offset was considered as inversion residue of atmospheric inhomogeneities during the racetrack manoeuvres, and consequently discarded. Also an analogous correction for the static pressure measurement has been discarded: at a flight altitude of $\approx 1000 \mathrm{~m}$ a.s.l. the maximum correction at $6 \mathrm{hPa}$ dynamic pressure $(0.51 \mathrm{hPa})$ corresponds to $\leq 10 \mathrm{~m}$ difference in altitude. This is in the order of the aircraft altitude fluctuations. With this the accepted error is in the same order as the uncertainty of the static pressure offset from tower flybys.

\subsubsection{Step E - wind squares}

Over all wind square flights the optimality criteria for horizontal and vertical wind components were averaged. Offsets for $\alpha(0.005 \mathrm{rad})$ and $\beta(-0.012 \mathrm{rad})$ were iteratively adjusted to minimize this single measure (Table 3 ).

\subsubsection{Step F - variance optimization}

From the variance optimization method a second set of offsets for $\alpha(0.017 \pm 0.003 \mathrm{rad})$ and $\beta(-0.014 \pm 0.001 \mathrm{rad})$ was found. The optimality criteria were applied to each leg individually and the offsets determined were averaged. The estimates differ from those for the wind squares by $0.6^{\circ}$ for $\alpha$ and by $0.1^{\circ}$ for $\beta$. While the deviation for $\beta$ lies within the installation repeatability, the deviation for $\alpha$ corresponds to $\approx 0.3 \mathrm{~m} \mathrm{~s}^{-1}$ uncertainty in the vertical wind (Table 4). The wing's upwash in Eq. (3), and its variation due to different aircraft trim was considered as one potential reason for this deviation: While flying level with similar power setting, flights in denser air in the atmospheric boundary layer (e.g. variance optimization flights) require a smaller lift coefficient, i.e. less wing pitch, than flights in the less dense air in the free atmosphere (e.g. wind square flights). That is $C L$ 

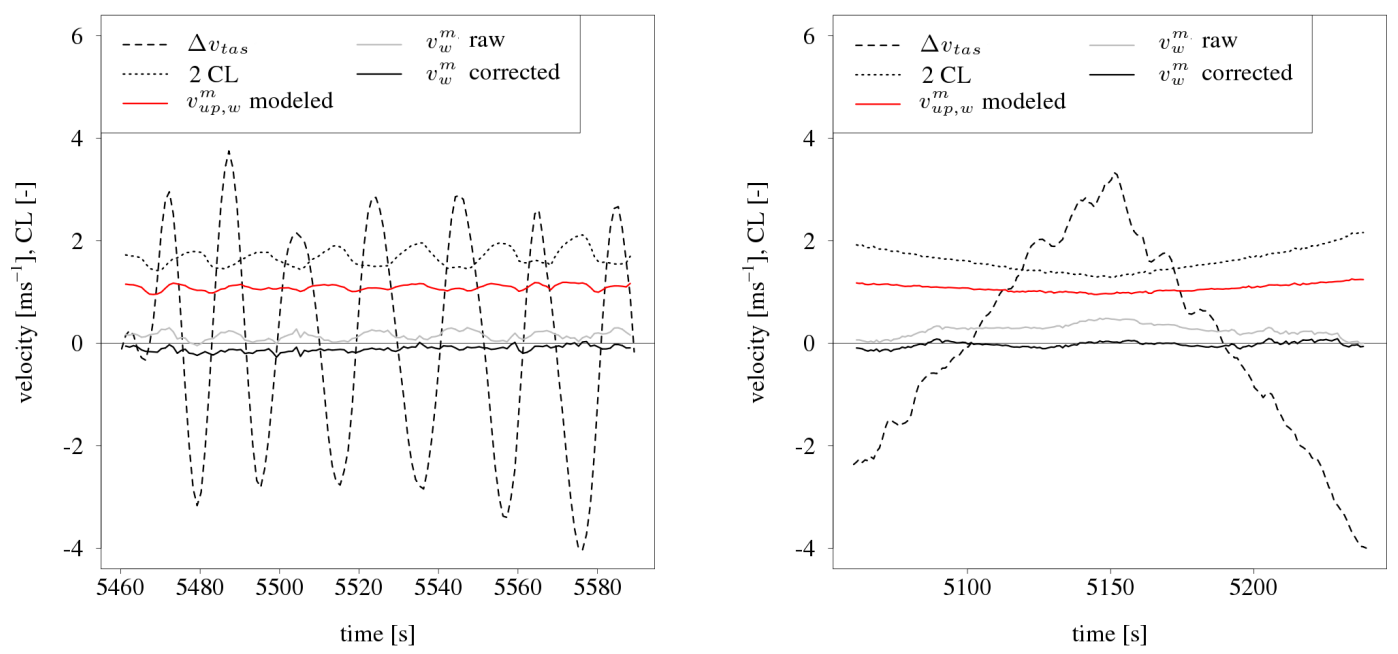

Fig. 8. Forced oscillation pattern (VW3, left) and level acceleration-deceleration pattern (VW1, right) on 25 June 2008 . For improved legibility the average is subtracted from true airspeed $\left(\Delta v_{\text {tas }}\right)$ and lift coefficient is inflated by the factor two $(2 C L)$. Displayed is the vertical wind $\left(v_{w}^{\mathrm{m}}\right)$ before (raw) and after (corrected) correction for dependence on the lift coefficient. For comparison the modelled upwash ( $\left.v_{\mathrm{up}, w}^{\mathrm{m}}\right)$ is presented, which was computed using Eq. (3) and decomposed and rotated from wing- into meteorological coordinates using Eq. (A13).

in Eq. (2) is inversely proportional to air density. For terrain following flights in the ABL vertical acceleration due to pilot input is likely to additionally alter the wing loading, and with it $C L$.

\subsubsection{Step $\mathbf{G}$ - vertical wind treatment}

Among all the wind components the vertical wind measurement is of prevailing importance to reliably compute EddyCovariance fluxes. Correspondingly its assessment and treatment is the centrepiece of this calibration procedure. To disentangle the comprehensive sequence of assessment and treatment, Step G is further divided into six sub-steps:

Step G1 - Net effect of aircraft trim and wing loading.

Step G2 - Reformulation of the upwash correction.

Step G3 - Parametrization of aircraft trim and wing loading effects.

Step G4 - Parametrization of offsets.

Step G5 - Iterative treatment of cross dependences.

Step G6 - Application to terrain following flight.

\subsubsection{Step G1 - net effect of aircraft trim and wing loading}

The net effect of changing aircraft trim and wing loading was investigated with the forced oscillation (VW3) flight pattern. During the flight on 25 June 2008 the wing pitching angle was modified by $\pm 5^{\circ}$. This results in a climb angle amplitude $>10^{\circ}$ (compared to $<5^{\circ}$ during terrain following flight) and a maximum vertical velocity of $|4| \mathrm{m} \mathrm{s}^{-1}$ (Fig. 8). It is evident that the modelled upwash ( $v_{\mathrm{up}}^{w}$ ) is proportional to the lift coefficient, as defined in Eq. (3). Assuming a constant vertical wind, not necessarily but likely approaching zero above the $\mathrm{ABL}$, measured variations in $v_{w}^{\mathrm{m}}$ are referred to as "net observed upwash". As opposed to the parametrization by Crawford et al. (1996) for fixed-wing aircraft, the net observed upwash at the five hole probe location is smaller by one order of magnitude but more variable, as well as phase inverted with $C L$. These findings are confirmed with the level acceleration - deceleration flight VW1 with a long period (180 s) and negligible vertical velocity (Fig. 8). With it a potential phase difference between airspeed and wing loading during the VW3 flight can be ruled out as explanation for the antagonistic relationship between $C L$ and the observed upwash. Introducing a lower proportionality factor to Eq. (3) could account for the particular properties of the WSMA wing. This would reduce the magnitude of the modelled upwash, but could not explain the higher variability as w ell as the phase inversion of the observed upwash. In contrast to FWA, the WSMA's wing-tip and trike nose approach each other with increasing airspeed (Sect. 4). The wing's centre of pressure is within $<10 \%$ chord length of the centre of gravity. Through this distance, wing pitching by $-5^{\circ}$ would result in a decrease of the normalized distance between centre of pressure and 5HP $(n)$, by $\approx-1 \%$. Though modelled upwash inversely varies with $n$ in Eq. (3), the approach of wing and trike alone can not explain the upwash phase inversion. Considering a change from high true airspeed (low lift coefficient) to low true airspeed (high lift coefficient) during level flight actually a number of effects contribute to the observed net upwash: (a) increase of upwash production from the wing according to Eq. (3), (b) decrease of wing circulation effective at the 5HP through larger distance and opening angle between 5HP and wing, and (c) decrease of propeller induced 
Table 6. Coefficients for static pressure $\left(p_{\mathrm{S}}\right)$, dynamic pressure $\left(p_{q}\right)$, differential pressures $\left(p_{\alpha}, p_{\beta}\right)$, static temperature $\left(T_{\mathrm{S}}\right)$, and flow angle measurements $(\alpha, \beta)$ during calibration steps A-G. Respective environments are laboratory (LAB), wind tunnel (TUN), comparison to ground based measurements (COMP), racetrack (RACE), wind square (SQUA), variance optimization (VARI) and vertical wind (VW) specific flight patterns. Coefficients are distinguished in offset (off) and slopes (slo), where applicable with lift coefficient in the upwash corrections (upw). Cross-calibration is referred to with the calibration steps in parentheses. Coefficients in parentheses were only used for intermediate calculations.

\begin{tabular}{|c|c|c|c|c|c|c|c|c|}
\hline Variable & Coefficient & A. LAB & B. TUN & C. COMP & D. RACE & E. SQUA & F. VARI & G. VW \\
\hline \multirow[t]{2}{*}{$p_{\mathrm{s}}$} & off $[\mathrm{hPa}]$ & -1.220 & & -2.26 & & & & \\
\hline & slo $[-]$ & 225.170 & & & & & & \\
\hline \multirow{2}{*}{$p_{q}$} & off $[\mathrm{hPa}]$ & -13.895 & 0.216 & & & & & \\
\hline & slo $[-]$ & 6.068 & 1.049 & & 1.085 & & & \\
\hline \multirow[t]{2}{*}{$p_{\alpha}$} & off [hPa] & -13.706 & & & & & & \\
\hline & slo $[-]$ & 6.088 & & & & & & \\
\hline \multirow[t]{2}{*}{$p_{\beta}$} & off $[\mathrm{hPa}]$ & -13.704 & & & & & & \\
\hline & slo $[-]$ & 6.060 & & & & & & \\
\hline \multirow[t]{2}{*}{$T_{\mathrm{s}}$} & off $[\mathrm{K}]$ & -33.821 & & & & & & \\
\hline & slo $[-]$ & 9.762 & & & & & & \\
\hline \multirow[t]{3}{*}{$\alpha$} & upw,off [rad] & & & & & $(0.005)$ & $(0.017)$ & $0.039(\mathrm{~F})$ \\
\hline & upw,slo [rad] & & & & & & & -0.027 \\
\hline & slo $[-]$ & & & & & & & $1(\mathrm{~F})$ \\
\hline \multirow[t]{3}{*}{$\beta$} & upw,off [rad] & & & & & $(-0.012)$ & $(-0.014)$ & $-0.004(\mathrm{E})$ \\
\hline & upw,slo (rad) & & & & & & & $-0.010(\mathrm{E})$ \\
\hline & slo $[-]$ & & & & & & & $1(\mathrm{~F})$ \\
\hline
\end{tabular}

upwash. The latter effects counteract the wing induced upwash. In addition (d) the shape of the aeroelastic wing, as well as (e) the flow around the trike change. Therefore the net upwash of a WSMA can neither be parametrized nor corrected with the Crawford et al. (1996) wing upwash model alone. Garman et al. (2008) on the other hand proposed to correct for upwash by considering the actual wing loading factor (LF), which carries information on the aircraft's vertical acceleration. In contrast to the study of Garman et al. (2008), WSMA weight, fuel level as well as dynamic pressure $\left(p_{q}\right)$ are known. Therefore $C L$ can be directly determined and used instead of LF. This has the advantage that information on the aircraft's trim, i.e. information on above effects (b)-(e), is included: as formulated in Eq. (2), $p_{q}$ carries information on $v_{\text {tas }}$ at given air density. Over eight independent flights of patterns VW1, VW2 and VW3 the observed net upwash is correlated with $C L(-0.53 \pm 0.16)$, change in $v_{\text {tas }}(0.57 \pm 0.16)$, and wing pitch $(-0.50 \pm 0.20)$. I.e. the application of control forces leads to a simultaneous change in both, the wind field and the lift coefficient. In the following section we will use this relationship to treat the effect of pilot input on the wind measurement.

\section{Step G2 - reformulation of the upwash correction}

Crawford et al. (1996) and Kalogiros and Wang (2002b) have shown that the upwash Eq. (3) can be reformulated as a function of $C L$ in the 5HP measured attack angle $(\alpha)$. Yet, as opposed to FWA, the WSMA is defined in two different coordinate systems, those of the wing (upwash) and the trike (5HP measurement, Fig. 2). Therefore an upwash correction in $\alpha$ would not explicitly consider the mobility of the trike in the wing circulation. As shown above only minor uncertainty would be introduced for pitching movements, though rolling movements and their possible influence would be left out. Consequently wind measurements during turning manoeuvres would not be covered, which however are not the subject of this study. In return correcting the upwash in $\alpha$ yields several advantages compared to explicitly modelling and subsequently subtracting the upwash: one explanatory variable is sufficient to explain the upwash variability effectively incident at the 5HP. With it a potential phase shift between variables measured in the wing and the trike body coordinate systems, as well as additional coordinate transformations are omitted. Therefore the net upwash variability was treated for straight and level flight (such as during EC soundings) using a linear model in $\alpha$ :

$$
\begin{aligned}
\alpha_{\infty} & =\alpha_{\mathrm{A}}-\alpha_{\text {upw }} \\
& =\alpha_{\mathrm{A}}-\left(\alpha_{\mathrm{upw}, \mathrm{off}}+\alpha_{\mathrm{upw}, \text { slo }} C L\right),
\end{aligned}
$$

with $\alpha_{\infty}$ the (desired) free air stream angle of attack, $\alpha_{\mathrm{A}}$ being the 5HP derived attack angle, and $\alpha_{\text {upw }}$ an additive attack angle provoked by the upwash with $\alpha_{\text {upw,off }}$ and $\alpha_{\text {upw, slo }}$ being its constant part and sensitivity on $C L$, respectively. As outlined above the complex interaction of wing upwash and aeroelasticity, distance and opening angle with the 5HP, propeller slipstream and flow around the trike is collectively correlated in $C L$. This offers the possibility of a dynamic 
treatment of the net flow distortion in one single explanatory variable. The purpose of this correction is to reposition the mean vertical wind under the effects of terrain following flight in the ABL, i.e. correct for its offset drift.

\section{Step G3 - parametrization of aircraft trim and wing loading effects}

For vertical wind specific flights (VW) above the ABL, $\alpha$ in Eq. (A11) was changed iteratively until yielding a vertical wind $\left(v_{w}^{\mathrm{m}}\right)$ of zero. Subtracting this inverse reference of $\alpha_{\infty}$ from $\alpha_{\mathrm{A}}$ gives us an estimate of $\alpha_{\text {upw }}$. To reduce scatter, $\alpha_{\text {upw }}$ was averaged after binning over increments of $0.01 C L$. From this binned and averaged data $\alpha_{\text {upw,off }}$ and $\alpha_{\text {upw,slo }}$ were obtained with a linear fit (Fig. 9). Scatter for the level acceleration-deceleration (VW1) flight and the forced oscillation (VW3) flight (both on 25 June 2008) is significantly reduced by implementing the binning procedure. Before binning, the VW1 flight shows a slight hysteresis, probably due to the accelerating- and decelerating legs. Non-binned values of the VW3 flight are considerably more scattered than for VW1. This can be attributed to the rising and sinking process of the aircraft and changing flow regimes about the wing during load change at the turning points. Fitted coefficients differed slightly between the two flights. The analysis was continued with the coefficients of the better determined VW1 flight $\left(R^{2}=0.85\right)$, which amount to $\alpha_{\text {up off }}=0.031 \mathrm{rad}$ and $\alpha_{\text {upw,slo }}=-0.027 \mathrm{rad}$. That is $\alpha_{\mathrm{A}}$ would be overestimated by $\approx 1.7^{\circ}$ if the WSMA could fly at zero lift. The effect decreases with slower flight at a rate of $\approx-1.7^{\circ}$ per $C L$. The correction reduces the vertical wind fluctuations for systematic deviations resulting from varying wing trim $(53 \%$, relative to the bias-adjusted overall fluctuation) and wing loading $(16 \%)$ for above named VW1 and VW3 flights, respectively. For the VW3 flight (Fig. 8) the decorrelation of $v_{w}^{\mathrm{m}}$ with $v_{\text {tas }}$ improves from 0.79 to -0.11 , and the decorrelation with wing pitch improves from -0.78 to 0.17 . Assuming zero vertical wind, RMSE and BIAS slightly improved from 0.17 and $0.15 \mathrm{~m} \mathrm{~s}^{-1}$ to 0.13 and $-0.11 \mathrm{~m} \mathrm{~s}^{-1}$, respectively. Lenschow (1986) proposed a $10 \%$ criteria for the effect of the aircraft's vertical velocity $\left(v_{\mathrm{gs}}^{\mathrm{m}, z}\right)$ on $v_{w}^{\mathrm{m}}$. It is employed as an operational limit by the Research Aviation Facility of the US National Centre for Atmospheric Research (NCAR, Tjernström and Friehe, 1991). Using the upwash correction this measure was improved from $3.8 \%$ to $2.7 \%$ $(\sigma)$. A slight trend in $v_{w}^{\mathrm{m}}$ remains. The correction was also applied to two smooth oscillation (VW2) patterns. The flight on 24 June 2008 was conducted in less calm air and two different power settings were applied (Fig. 10). The correction changed overall RMSE and BIAS from 0.26 and $0.13 \mathrm{~m} \mathrm{~s}^{-1}$ to 0.25 and $-0.13 \mathrm{~m} \mathrm{~s}^{-1}$, respectively. That is the quality measures did not indicate significant improvement, but the vertical wind BIAS was inverted. However after correction the change in power settings $\left(4800-5000 \mathrm{~s}: v_{\text {tas }}=26 \mathrm{~m} \mathrm{~s}^{-1}\right.$,

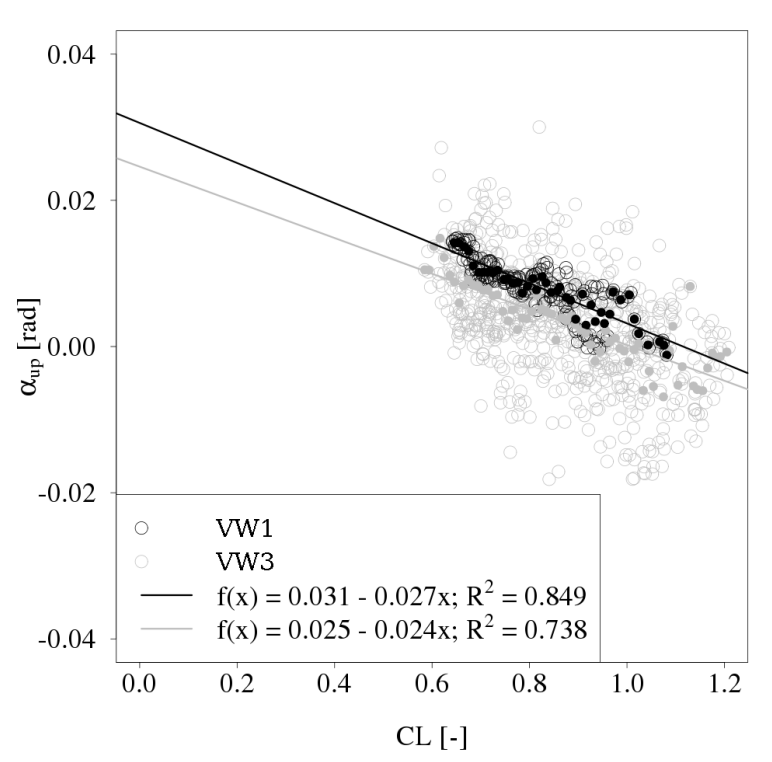

Fig. 9. Upwash attack angle $\left(\alpha_{\text {up }}\right)$ as function of the lift coefficient $(C L)$ for two vertical wind specific flight patterns on 25 June 2008 (VW1, VW3). $\alpha_{\text {up }}$ is the difference of attack angle as measured by the five hole probe and the inverse reference of the free airstream attack angle (Sect. 4.1 Step G3). Open circles depict the entire $1 \mathrm{~Hz}$ dataset. Full circles are averages after binning over increments of $0.01 C L$.

5200-5400 s: $\left.v_{\text {tas }}=28 \mathrm{~m} \mathrm{~s}^{-1}\right)$ did not alter the offset in $v_{w}^{\mathrm{m}}$ anymore (correlation of $v_{w}^{\mathrm{m}}$ with $v_{\text {tas }}$ decreased from 0.42 to 0.21 ). The dependence on vertical movement decreased only slightly from $14.7 \%$ to $13.5 \%(\sigma)$, however correlation of $v_{w}^{\mathrm{m}}$ with $v_{\mathrm{gs}}^{\mathrm{m}, z}$ is $<0.02$. Due to the less calm atmosphere $\sigma$ might not be representative for their cross dependence in this case. The VW2 flight on 25 June 2008 was again conducted in calm air at $28 \mathrm{~m} \mathrm{~s}^{-1}$ true airspeed (Fig. 10). Here our correction leads to a change in RMSE and BIAS from 0.22 and $0.20 \mathrm{~m} \mathrm{~s}^{-1}$ to 0.09 and $-0.02 \mathrm{~m} \mathrm{~s}^{-1}$. After correction the dependence on vertical aircraft movement increased slightly from $7.7 \%$ to $8.3 \%(\sigma)$, which still well agrees with the limit used by NCAR.

\section{Step G4 - parametrization of offsets}

We have learned from the VW3 pattern (Fig. 8), that calculation of $v_{w}^{\mathrm{m}}$ was improved for flights which include changes in aircraft trim and lift. From the VW2 pattern we have seen that $v_{w}^{\mathrm{m}}$ is independent of slow aircraft rising and sinking manoeuvres, and the decorrelation of $v_{w}^{\mathrm{m}}$ with $v_{\text {tas }}$ was improved (Fig. 10). Hence the WSMA wind measurement fulfils the requirements to be used during terrain following flights in the ABL. Yet after applying the correction, BIAS in $v_{w}^{\mathrm{m}}$ was negative, ranging from -0.13 to $-0.02 \mathrm{~m} \mathrm{~s}^{-1}$. Assuming independence of $v_{w}^{\mathrm{m}}$ from $v_{\text {tas }}$, the detected BIAS depends on $\alpha_{\text {up }, \text { off }}$ in Eq. (7). Both, $\alpha_{\text {up,off }}$ and $\alpha_{\text {upw,slo }}$ were determined 

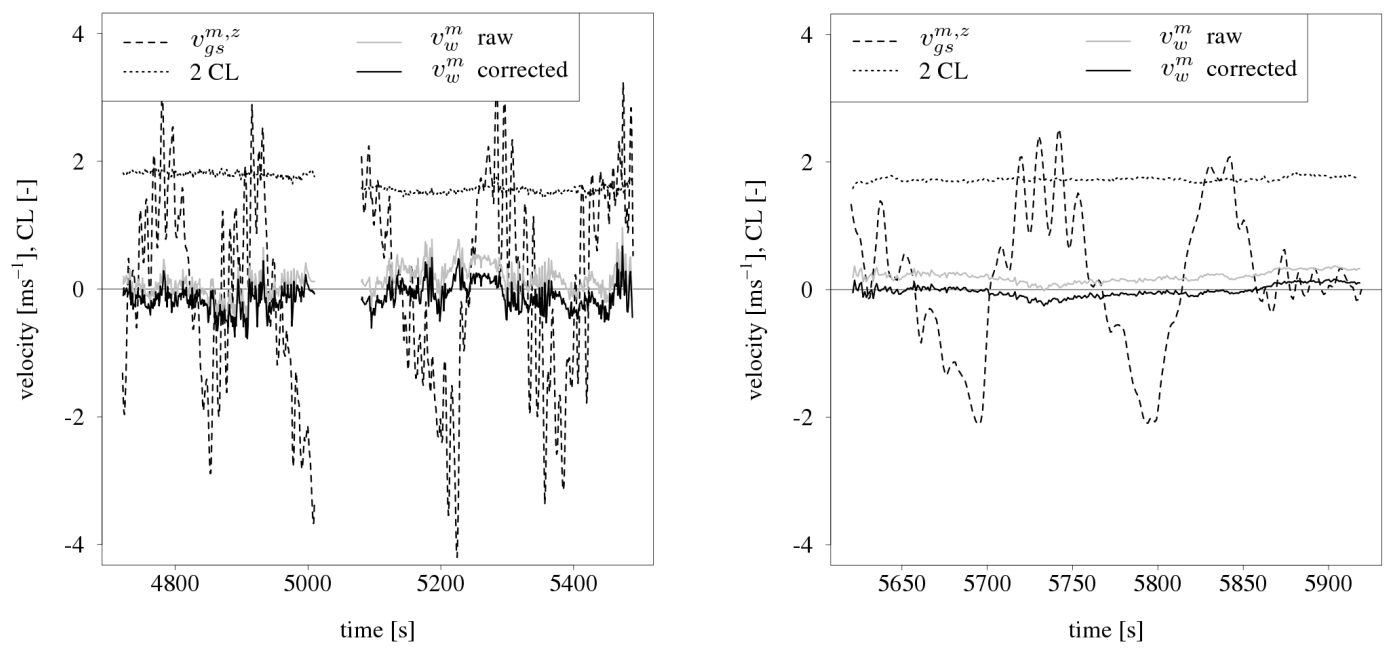

Fig. 10. Smooth oscillation flights (VW2) on 24 June 2008 (left) and 25 June 2008 (right). In addition to the variables explained in Fig. 8 the vertical aircraft velocity $\left(v_{\mathrm{gs}}^{\mathrm{m}, z}\right)$ is shown. Additional information is given in Sect. 4.1 Step G3.

using the VW1 flight on 25 June 2008 during ambiguous cyclonality atop and below measurement altitude (Table 3 ). In Fig. 9 the determination of $\alpha_{\text {upw, slo }}$ depends on the change of $C L$, while the offset $\alpha_{\text {up,off }}$ depends on the ambient vertical wind. During the inverse reference procedure $v_{w}^{\mathrm{m}}$ was forced to zero while, e.g. in an anticyclone, subsidence occurs. In such a situation $\alpha_{\text {up, off }}$ would be underestimated. During the VW flights on 24 and 25 June 2008, cyclonality and BIAS in $v_{w}^{\mathrm{m}}$ both changed. While $\alpha_{\text {upw,slo }}$ is insensitive, no constant $\alpha_{\text {up,off }}$ could be determined from the VW flights. At this point the variance optimization flights in the ABL are of importance. Assuming constant ABL height (approximately fulfilled for noontime EC soundings) the second optimality criteria states that due to mass conservation $\overline{v_{w}^{\mathrm{m}}}$ approaches zero for a sufficiently high number of datasets. With it $\alpha_{\text {up,off }}$ was determined directly from ABL flights. Using the first variance optimization optimality criteria, i.e. the minimization of the wind variance, also $\alpha$ and $\beta$ slopes were tested.

\section{Step G5 - iterative treatment of cross dependences}

An approach similar to Eq. (7), the explanation of upwash in $\alpha$, was used to explain sidewash in $\beta$ :

$\beta_{\infty}=\beta_{\mathrm{A}}-\left(\beta_{\text {upw }, \text { off }}+\beta_{\text {upw }, \text { slo }} C L\right)$,

using the calibration criteria of the wind square flights for parametrization. According to Eq. (A11) cross dependence occurs between the parametrizations in $\alpha$ and $\beta$. This problem was solved by iterating the optimality criteria for wind square, vertical wind, and variance optimization flights in sequence. The order of this sequence, i.e. first optimizing for the horizontal wind components $\left(v_{u v}^{\mathrm{m}}\right)$, then for the vertical wind component $\left(v_{w}^{\mathrm{m}}\right)$, was chosen due to their different order of magnitude and importance for EC application.
Spurious contamination with $v_{w}^{\mathrm{m}}$ would change $v_{u v}^{\mathrm{m}}$ only by a tiny fraction. The other way around however would result in considerably higher contamination in $v_{w}^{\mathrm{m}}$. The final calibration coefficients are summarized in Table 6 .

Compared to the upwash parametrization, sidewash was found to be modest ( $\left.\beta_{\text {upw,off }}=-0.004 \mathrm{rad}\right)$ and less sensitive regarding $C L$ ( $\beta_{\text {upw,slo }}=-0.010 \mathrm{rad}$, Table 6$)$. This is in line with the initial attempt to resolve the circulation around the wing and the trike movement explicitly (Fig. 5). The findings also confirm our initial hypothesis that flow transverse to the pressure probe requires less correction than in vertical direction (Sect. 2.1): leaving dynamic considerations aside (i.e. lift coefficient is zero), the magnitude of the sideslip angle correction is one order of magnitude lower than the attack angle correction ( $0.039 \mathrm{rad}$, offsets in Table 6). For a true airspeed of $30 \mathrm{~m} \mathrm{~s}^{-1}$ this affects the wind measurement to approximately $-0.1 \mathrm{~m} \mathrm{~s}^{-1}$ and $1.2 \mathrm{~m} \mathrm{~s}^{-1}$, respectively. The transverse distortions increase and the vertical distortions decrease at a ratio of $\approx 1: 3$, when considering interactions with propeller and wing (i.e. non-zero lift coefficient, slopes in Table 6).

\section{Step G6 - application to terrain following flight}

The uncertainty of the correction during terrain following flight can be assessed from the regression errors, e.g. in the upwash attack angle for the vertical wind. In Step G3 the level acceleration-deceleration flight was used to calibrate the regression slope. This slope did not differ significantly compared to the forced oscillation flight, with $-0.027 \pm 0.002$ and $-0.024 \pm 0.002$, respectively. In Step G4 we used $12 \mathrm{ABL}$ flights or $360 \mathrm{~km}$ of flight data to parametrize the regression offset $(0.039 \pm 0.003)$. The combined errors in slope and intercept were applied to the terrain 
following flight on 31 July 2009. The resulting uncertainty in the vertical wind measurement is within $0.1 \mathrm{~m} \mathrm{~s}^{-1}$ (RMSE) for the mean and $1 \%$ for the variance. This compares to the magnitude of the correction, which is in the order of $0.5 \mathrm{~m} \mathrm{~s}^{-1}$ for the mean and $3 \%$ for the variance, respectively.

Many variables in the ABL scale with distance from the exchange surface (e.g. Mahrt, 2000; Mahrt et al., 2001). Interpretable results can be achieved by flying at approximately constant altitude above ground (e.g. Betts et al., 1990; Vickers and Mahrt, 1997). Yet many terrestrial surfaces are not ideally flat. During terrain following measurements we focus on mostly horizontal flight tracks between 40 and $80 \mathrm{~km}$ extend. Typical altitude gradients during such flight patterns are $100 \mathrm{~m}$ vertical on $10 \mathrm{~km}$ horizontal, and rarely reach $\pm 5^{\circ}$ climb angle. In order to adjust aircraft altitude, the pilot anticipates the terrain contours at a scale of kilometres. At typical airspeeds this corresponds to an adjustment of power setting and wing pitch through the pilot at frequencies $<0.1 \mathrm{~Hz}$. In addition to the low frequency control forces, also external forces due to atmospheric turbulence and mesoscale motions meet in the hangpoint. An increase in the vertical wind variance in the order of $1 \%$ would result when applying the correction for low frequency pilot actions to the entire frequency spectrum. Consequently the correction is only applied to frequencies $<0.1 \mathrm{~Hz}$. This is achieved by calculating Eqs. (7), (8) through a third order Savitzky-Golay complementary filter (e.g. Chen et al., 2004). The treatment leads to a decrease in the vertical wind variance in the order of $-3 \%$. This is expected since the impact of the low frequency pilot actions on the wind measurement is removed.

Low frequency atmospheric motions, such as turbulent organized structures, overlap with pilot actions in frequency space. The effect of low frequency atmospheric motions on the correction can be estimated with a simple example. In a large-scale downdraft of velocity $w_{\mathrm{d}}$ an aircraft of mass $m$ and airspeed $v_{\text {tas }}$ has to produce the total lift $L=m a_{z}(1+$ $w_{\mathrm{d}} / v_{\text {tas }}$ ), with $a_{z}$ being the acceleration perpendicular to the airstream. As compared to zero vertical wind conditions the lift, and with it the lift coefficient in Eq. (2), is changed by the ratio of $w_{\mathrm{d}} / v_{\text {tas }}$. For the flight on 31 July 2009 a ratio of $\pm 1 \%$ is equivalent to $w_{\mathrm{d}}= \pm 0.27 \mathrm{~m} \mathrm{~s}^{-1}$, a typical value for turbulent organized structures in the ABL (e.g., Steinfeld et al., 2007). To test the influence on the correction a sinusoidal signal with amplitude $1 \%$ and frequency $0.01 \mathrm{~Hz}$ was added to the measured lift coefficient. The maximum deviation from the undisturbed measurement is within $\pm 3 \%$, or sub centimetre. The variance of the vertical wind is changed by $<0.01 \%$. We conclude that the correction can be applied to the entire frequency range $\leq 0.1 \mathrm{~Hz}$ without introducing significant uncertainty to the wind measurement.

\subsection{Wind measurement evaluation}

After completing all calibration steps, the wind measurement with the WSMA was evaluated. The evaluation was carried out in three lines of analysis, (a) uncertainty propagation, (b) wind square flights, and (c) comparison to ground based wind measurements. For a true airspeed of $27 \mathrm{~m} \mathrm{~s}^{-1}$ the propagation of uncertainties in sensors (flow angle differential pressures, dynamic- and static pressures, static temperature, and water vapour pressure), their basic calibration and wind model description yield an uncertainty $(\sigma)$ of $0.76^{\circ}$, $0.76^{\circ}$, and $0.34 \mathrm{~m} \mathrm{~s}^{-1}$ in attack angle $(\alpha)$, sideslip angle $(\beta)$ and true airspeed, respectively (Table 5). Feeding the input uncertainty Eq. (B1) with these quantities extends the uncertainty propagation to the wind components (Table 4). The input error is formulated worst case, and parametrized for the $95 \%$ confidence intervals of the attitude and flow angles. In addition the uncertainty of the inertial navigation system $\left(0.02 \mathrm{~m} \mathrm{~s}^{-1}\right)$ was considered in the wind vector Eq. (A1). This allows to estimate the maximum potential uncertainty by sensor setup and wind model description. The results for the maximum overall uncertainty bounds are 0.66 and $0.57 \mathrm{~m} \mathrm{~s}^{-1}$ for the horizontal $\left(v_{u v}^{\mathrm{m}}\right)$ and vertical $\left(v_{w}^{\mathrm{m}}\right)$ wind components, respectively.

Figure 11 shows the results of all wind square flights. For wind velocities $>2 \mathrm{~m} \mathrm{~s}^{-1} v_{u v}^{\mathrm{m}}$ determined for individual legs deviate less than $10 \%$ from the average for the entire square. The residuals did not scale with the average wind velocity, to a greater degree they are likely to result from an incomplete removal of wind field inhomogeneities over the $12 \mathrm{~km}$ long flight paths. Therefore a horizontal wind velocity of $2 \mathrm{~m} \mathrm{~s}^{-1}$ can not be considered as a detection limit for wind measurements from WSMA. Also no systematic deviation for aircraft orientation could be detected. However $v_{w}^{\mathrm{m}}$ shows a slight sensitivity of -0.05 on $v_{\text {tas }}\left(R^{2}=0.46\right)$. Using the cardinal direction evaluation criteria Eq. (6), RMSE in $\alpha_{\infty}, \beta_{\infty}$ and $\left|\boldsymbol{v}_{\text {tas }}^{\mathrm{m}}\right|$ were computed to $0.31,0.33$ and $0.26 \mathrm{~m} \mathrm{~s}^{-1}$, respectively. These compare well to the results from the uncertainty propagation (Tables 5 and 4 ), which amount to $0.31,0.36$ and $0.34 \mathrm{~m} \mathrm{~s}^{-1}$ for $\alpha_{\mathrm{A}}, \beta_{\mathrm{A}}$ and $v_{\text {tas }}$, respectively.

Figure 12 shows a qualitative comparison of WSMA and ground based wind measurements for the flight on 15 October 2008. The vertical profile shows an equal number of flights at 24 and $27 \mathrm{~m} \mathrm{~s}^{-1}$ true airspeed. Despite one outlier in $v_{v}^{\mathrm{m}}$ and $v_{w}^{\mathrm{m}}$ at $120 \mathrm{~m}$ a.g.l., no distinct differences in average wind velocities between ground based measurements and WSMA are apparent. The comparability of WSMA and ground based wind measurement was further quantified by calculating RMSE and BIAS for all measurements accepted for the comparison (Table 3). The impact of calibration steps $\mathrm{C}-\mathrm{G}$ on these measures is displayed in Fig. 13. The measurement of the horizontal wind components $\left(v_{u v}^{\mathrm{m}}\right)$ was mainly improved (14\%, relative to the initial uncertainty) by means of the in-flight dynamic pressure correction (step D). After the wind square analysis (step E) the measurement was not further improved nor deteriorated. Yet the vertical wind measurement $\left(v_{u v}^{\mathrm{m}}\right)$ receives its greatest improvement (31\%) during steps F-G, i.e. variance optimization and vertical wind specific patterns: During these steps BIAS and 

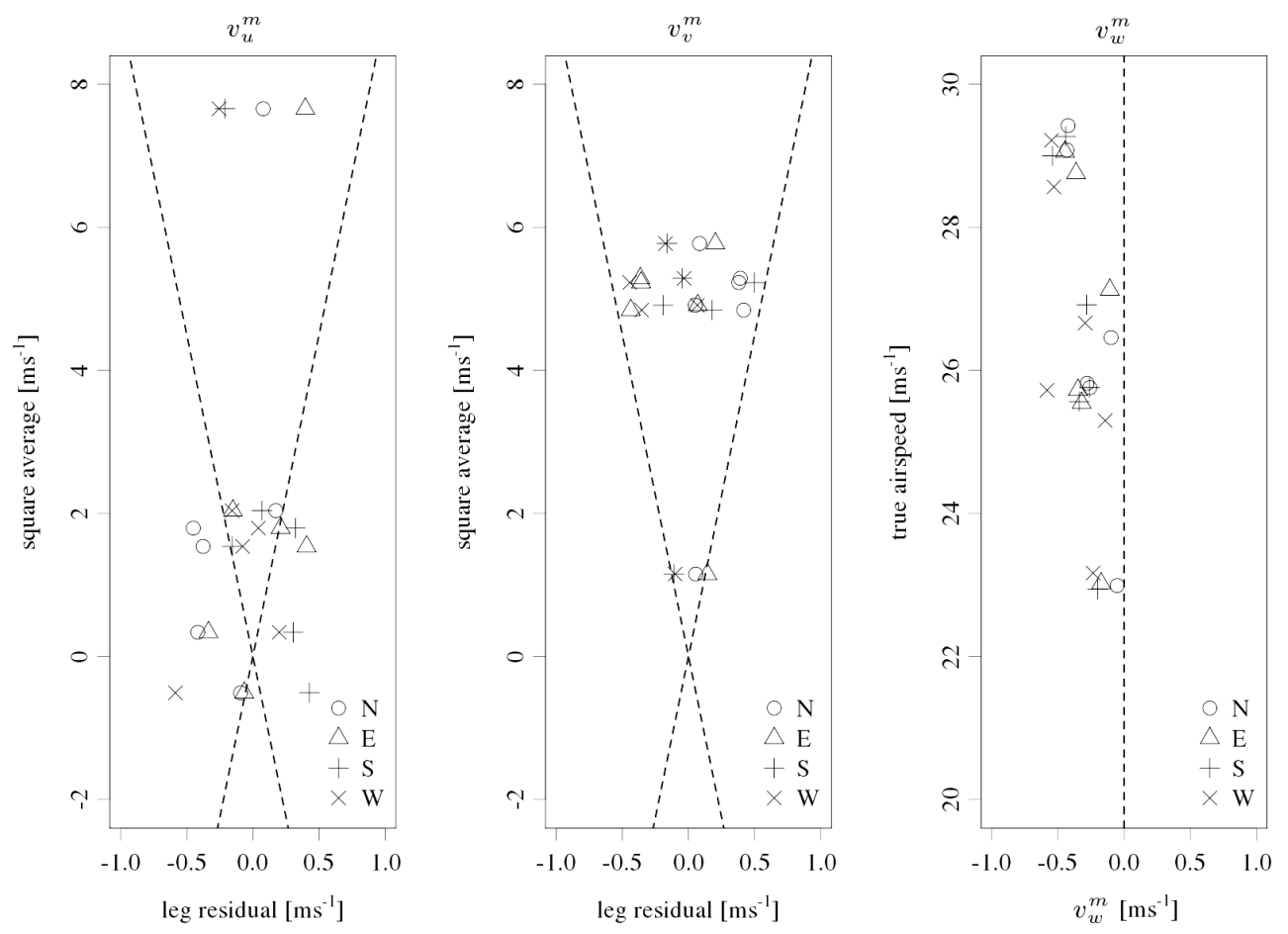

Fig. 11. Results from the wind square flights. For the horizontal wind components $\left(v_{u v}^{\mathrm{m}}\right)$ the $\mathrm{x}$-axis displays the residuals (leg average-square average), while the y-axis shows the wind magnitude. In contrast the vertical wind component $\left(v_{w}^{\mathrm{m}}\right)$ is plotted against the true airspeed. Flight legs are depicted with different symbols according to their position in the square pattern. Dashed lines indicate a $10 \%$ criteria for $v_{u v}^{\mathrm{m}}$, and the zero line for $v_{w}^{\mathrm{m}}$.

dBIAS, i.e. its dependence on $v_{\text {tas }}$, were reduced. In contrast to the findings from the wind square analysis, with a sensitivity of $\approx+0.05$ a slight positive dependence of all wind components on $v_{\text {tas }}$ remained. Considering all data couples between WSMA and ground based measurements, RMSE and BIAS amount to 0.50 and $-0.07 \mathrm{~m} \mathrm{~s}^{-1}$ for $v_{u v}^{\mathrm{m}}$ and 0.37 and $-0.10 \mathrm{~m} \mathrm{~s}^{-1}$ for $v_{w}^{\mathrm{m}}$, respectively. In addition to the above mentioned outlier, two more suspects were identified for the flight on 18 October 2008, again concurrent for $v_{v}^{\mathrm{m}}$ and $v_{w}^{\mathrm{m}}$. A possible explanation is the increased land surface heterogeneity sensed by the aircraft while travelling through the wind field. On the northern and western limbs of the aircraft cross pattern, forest patches of $\geq 200 \mathrm{~m}$ edge length interrupt the flat arable land immediately upwind. Therefore WSMA measurements can include turbulence and wake effects generated at the forest edges. In contrast tower measurements are not subject to comparable roughness changes until $\approx 2 \mathrm{~km}$ in upwind direction. Omitting the three outliers from the statistics, RMSE and BIAS between WSMA and ground based measurements improve to 0.39 and $-0.11 \mathrm{~m} \mathrm{~s}^{-1}$ for $v_{u v}^{\mathrm{m}}$ and 0.27 and $-0.10 \mathrm{~m} \mathrm{~s}^{-1}$ for $v_{w}^{\mathrm{m}}$, respectively.

\subsection{Discussion}

Distortions of the wind measurement originating from the interactions of the aeroelastic wing, propeller and trike structural features were successfully corrected for conditions approximating straight, terrain following flight. Yet the treatments integral to Eqs. (A7), (7) and (8) leave room for improvement: Compared to ground based measurements the aircraft underestimated the wind components $\approx-0.1 \mathrm{~m} \mathrm{~s}^{-1}$. A possible reason could be the discarded offset during the dynamic pressure $\left(p_{q}\right)$ in-flight calibration (Sect. 4.1). Rather forcing the linear fit to zero would slightly enhance the slope of $p_{q}$ and with it compliance to the aircraft's inertial speed.

During the wind square and comparison flights contradictory sensitivities (regression slope -0.05 versus +0.05 ) of the wind components on the true airspeed were found. For the variability in $v_{\text {tas }}$ during a thermally turbulent flight in the atmospheric boundary layer $\left(\sigma=1.24 \mathrm{~m} \mathrm{~s}^{-1}\right.$, Fig. 4) this corresponds to $\pm 0.06 \mathrm{~m} \mathrm{~s}^{-1}$ deviation in the wind components. Since this deviation is one order of magnitude lower than the system's input uncertainty, it was not further treated.

The lift coefficient is used as sole explanatory variable for the observed net upwash in the linear calibration models Eqs. (7) and (8). This treats the influence of aircraft trim (i.e. dynamic pressure) and lift (i.e. loading factor) on the wind measurement with similar sensitivity. The study by Visbal and Shang (1989) however shows that the flow field response of airfoils to pitch oscillations depends on the excitation frequency. With the Fourier method proposed by Kalogiros and Wang (2002b) the frequency dependence of 

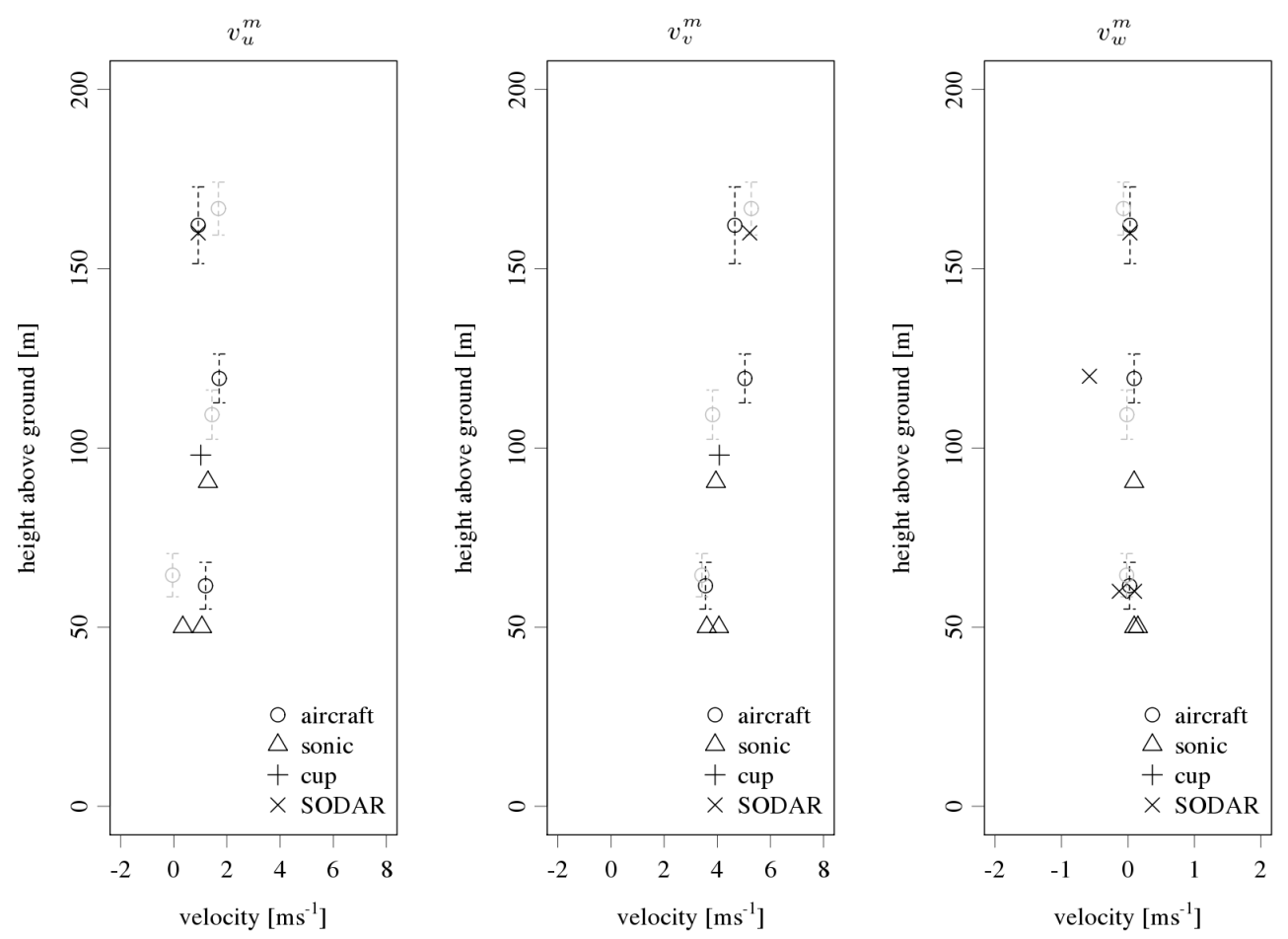

Fig. 12. Vertical profiles for horizontal $\left(v_{u v}^{\mathrm{m}}\right)$ and vertical $\left(v_{w}^{\mathrm{m}}\right)$ wind components of simultaneous ground based and weight-shift microlight aircraft measurements on 15 October 2008, 14:50-16:00 CET. Different symbols indicate the different wind sensors. Black circles represent aircraft measurements at $24 \mathrm{~m} \mathrm{~s}^{-1}$ true airspeed, while grey circles represent measurements at $27 \mathrm{~m} \mathrm{~s}^{-1}$ true airspeed. Vertical error bars indicate one standard deviation of the aircraft altitude.

the wing induced upwash can be modelled for FWA. The distinct difference from time domain methods is an amplified $(\approx 20 \%)$ upwash correction in the inertial subrange of atmospheric turbulence compared to lower frequencies. Due to little contributions of the inertial subrange, the effect on the eddy flux measurement at flight altitude $(\leq 4 \%)$ is however relatively small. At the same time a transformation from the wing to the trike coordinate system would be required, carrying a potentially variable phase difference. Moreover the interactions with propeller and trike, resulting in the net flow distortion, remain untreated. Isolating these interactions would require considerably more in-flight data and analytical effort. In return such procedure could address forenamed dependence of the wind components on $v_{\text {tas }}$ and additionally allow for superior wind measurements during turning manoeuvres.

\section{Conclusions}

We have shown that carefully computed wind vector measurements using a weight-shift microlight aircraft are not inferior to those from other airborne platforms. A $10 \%$ limit of contamination of the wind components by the aircraft movement, as used by the US National Centre for Atmospheric Research, was fulfilled even during severe vertical manoeuvring. For flights including rising and sinking of the aircraft, such as during terrain following Eddy-Covariance applications, three independent lines of analysis yield comparable uncertainty. This convergence is remarkable and emphasizes the integrity of sensing elements and wind model description. The procedure further enables to quantify the overall operational uncertainty (root mean square error) to $0.4 \mathrm{~m} \mathrm{~s}^{-1}$ for the horizontal and $0.3 \mathrm{~m} \mathrm{~s}^{-1}$ for the vertical wind components.

Independent consideration of trike movement and wing circulation according to the fixed-wing aircraft theory was not successful. Instead flow distortion of fuselage, propeller and wing were minimized by an approach integrated in the dynamic pressure and flow angle computations. The magnitude of distortion was treated as slope correction in the dynamic pressure computation. The distortion's distribution in components longitudinal, transverse and vertical to the wind measurement was subsequently parametrized in the attackand sideslip angle computations. The lift coefficient was successfully used as sole variable explaining the upwash distribution, containing in it the effects of aircraft trim and lift. After the treatment an inconclusive dependence of the vertical wind measurement on the aircraft's true airspeed remained. In-flight tests relate this dependence to an uncertainty of $0.06 \mathrm{~m} \mathrm{~s}^{-1}$ in the vertical wind measurement. As compared to ground measurements the final wind components were marginally underestimated by the aircraft $\left(\approx-0.1 \mathrm{~m} \mathrm{~s}^{-1}\right)$. 

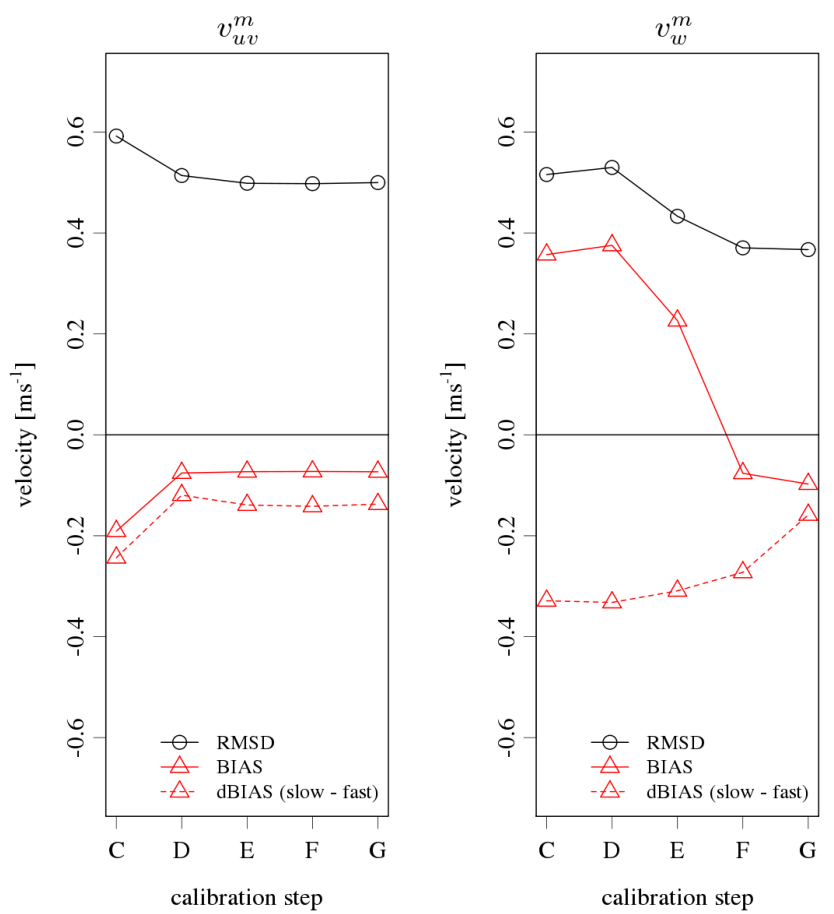

Fig. 13. Influence of the calibration steps $\mathrm{C}-\mathrm{G}$ on root mean square error (RMSE) and bias (BIAS) between weight-shift microlight aircraft and all simultaneous ground based measurements of the horizontal $\left(v_{u v}^{\mathrm{m}}\right)$ and the vertical $\left(v_{w}^{\mathrm{m}}\right)$ wind components. dBIAS indicates the difference in BIAS between measurements at 27 and $24 \mathrm{~m} \mathrm{~s}^{-1}$ true airspeed.

Our findings emphasize that the 3-D wind vector can be measured reliably from a highly transportable and low-cost weight-shift microlight aircraft. Hence the necessary basis is provided for the study of precision and spectral quality of the wind measurement, which is prerequisite for reliable EddyCovariance flux measurements. This brings the weight-shift microlight aircraft platform an important step closer towards a fullfeatured environmental research aircraft.

\section{Supplementary material related to this article is available online at: http://www.atmos-meas-tech.net/4/1421/2011/ amt-4-1421-2011-supplement.pdf.}

Acknowledgements. Special recognition has to be given to Josef-Michael Burger, Matthias Mauder, Frank Neidl, Rainer Steinbrecher and Rose Zuurbier at the Karlsruhe Institute of Technology, Institute for Meteorology and Climate Research. Burger and Zuurbier carried out the bulk of the wind-tunnel measurements, whereas Mauder contributed his invaluable micrometeorological advise. Neidl programmed and continuously maintained the data acquisition system, while Steinbrecher initiated wind- and flux measurements with the weight-shift microlight aircraft in the first place. Our gratefulness to Xunhua Zheng and her work-group at the Chinese Academy of Sciences, Institute of Atmospheric
Physics, who was hosting our project and providing indispensable infrastructure. We are much obliged to Frank Beyrich of the German Meteorological Service, Richard-Aßmann-Observatory, who permitted us to carry out the evaluation flights and provided us with the corresponding SODAR- and tower data for this study. Our thanks to Jens Bange and Aline van den Kroonenberg of the Technical University of Braunschweig, Institute of Aerospace Systems (now Eberhard Karls University of Tübingen, Institute for Geoscience), for their tireless advise. Stipend funding by the German Academic Exchange Service, Helmholtz Association of German Research Centrers, China Scholarship Council and the European Union under the Science and Technology Fellowship China is acknowledged. The flight in Inner Mongolia was funded by the German Research Foundation, research group 536 "Matter fluxes in grasslands of Inner Mongolia as influenced by stocking rate". The publication was funded by the German Research Foundation and Open Access Publishing Fund of the Karlsruhe Institute of Technology.

Edited by: J.-P. Pommereau

\section{References}

Baldocchi, D., Falge, E., Gu, L., Olson, R., Hollinger, D., Running, S., Anthoni, P., Bernhofer, C., Davis, K., Evans, R., Fuentes, J., Goldstein, A., Katul, G., Law, B., Lee, X., Malhi, Y., Meyers, T., Munger, W., Oechel, W. U. K., Pilegaard, K., Schmid, H., Valentini, R., Verma, S., Vesala, T., Wilson, K., and Wofsy, S.: FLUXNET: A new tool to study the temporal and spatial variability of ecosystem-scale carbon dioxide, water vapour, and energy flux densities, B. Am. Meteorol. Soc., 82, 2415-2434, 2001

Bange, J. and Roth, R.: Helicopter-borne flux measurements in the nocturnal boundary layer over land - a case study, Bound.-Lay. Meteorol., 92, 295-325, 1999.

Betts, A. K., Desjardins, R. L., Macpherson, J. I., and Kelly, R. D.: Boundary-layer heat and moisture budgets from FIFE, Bound.Lay. Meteorol., 50, 109-138, 1990.

Beyrich, F., Leps, J. P., Mauder, M., Bange, J., Foken, T., Huneke, S., Lohse, H., Ludi, A., Meijninger, W. M. L., Mironov, D., Weisensee, U., and Zittel, P.: Area-averaged surface fluxes over the LITFASS region based on Eddy-Covariance measurements, Bound.-Lay. Meteorol., 121, 33-65, 2006.

Bissolli, P. and Dittmann, E.: The objective weather type classification of the German Weather Service and its possibilities of application to environmental and meteorological investigations, Meteorol. Z., 10, 253-260, 2001.

Bohn, D. and Simon, H.: Mehrparametrige Approximation der Eichräume und Eichflächen von Unterschall- bzw. Überschall5-Loch-Sonden, Archiv für Technisches Messen und Meßtechnische Praxis, 470, 31-37, 1975.

Boiffier, J.-L.: The Dynamics of Flight: The Equations, Wiley, 1998.

Brown, E. N., Friehe, C. A., and Lenschow, D. H.: The use of pressure-fluctuations on the nose of an aircraft for measuring air motion, J. Clim. Appl. Meteorol., 22, 171-180, 1983. 
Chen, J., Jonsson, P., Tamura, M., Gu, Z. H., Matsushita, B., and Eklundh, L.: A simple method for reconstructing a high-quality NDVI time-series data set based on the Savitzky-Golay filter, Remote Sens. Environ., 91, 332-344, 2004.

Cook, M. V.: The theory of the longitudinal static stability of the hang-glider, Aeronaut. J., 98, 292-304, 1994.

Cook, M. V. and Spottiswoode, M.: Modelling the flight dynamics of the hang glider, Aeronaut. J., 110, 1-20, 2006.

Cooper, W. A. and Rogers, D.: Effects of air-flow trajectories around aircraft on measurements of scalar fluxes, J. Atmos. Ocean. Tech., 8, 66-77, 1991.

Crawford, T. L. and Dobosy, R. J.: A sensitive fast-response probe to measure turbulence and heat-flux from any airplane, Bound.Lay. Meteorol., 59, 257-278, 1992.

Crawford, T., Dobosy, R., and Dumas, E.: Aircraft wind measurement considering lift-induced upwash, Bound.-Lay. Meteorol., 80, 79-94, 1996.

Desjardins, R. L., MacPherson, J. I., Mahrt, L., Schuepp, P., Pattey, E., Neumann, H., Baldocchi, D., Wofsy, S., Fitzjarrald, D., McCaughey, H., and Joiner, D. W.: Scaling up flux measurements for the boreal forest using aircraft-tower combinations, J. Geophys. Res., 102, 29125-29133, 1997.

Egger, J., Bajrachaya, S., Heinrich, R., Kolb, P., Lammlein, S., Mech, M., Reuder, J., Schaper, W., Shakya, P., Schween, J., and Wendt, H.: Diurnal winds in the Himalayan Kali Gandaki valley, Part III: Remotely piloted aircraft soundings, Mon. Weather Rev., 130, 2042-2058, 2002.

Foken, T.: Temperaturmessungen mit dünnen Platindrähten, Z. Meteorol., 29, 299-307, 1979.

Foken, T. and Wichura, B.: Tools for quality assessment of surfacebased flux measurements, Agr. Forest Meteorol., 78, 83-105, 1996.

Garman, K. E., Hill, K. A., Wyss, P., Carlsen, M., Zimmerman, J. R., Stirm, B. H., Carney, T. Q., Santini, R., and Shepson, P. B.: An airborne and wind tunnel evaluation of a wind turbulence measurement system for aircraft-based flux measurements, J. Atmos. Ocean. Tech., 23, 1696-1708, 2006.

Garman, K. E., Wyss, P., Carlsen, M., Zimmerman, J. R., Stirm, B. H., Carney, T. Q., Santini, R., and Shepson, P. B.: The contribution of variability of lift-induced upwash to the uncertainty in vertical winds determined from an aircraft platform, Bound.-Lay. Meteorol., 126, 461-476, 2008.

Gratton, G. B.: The weightshift-controlled microlight aeroplane, Proceedings of the Institution of Mechanical Engineers Part G, J. Aerospace Eng., 215, 147-154, 2001.

Hobbs, S., Dyer, D., Courault, D., Olioso, A., Lagouarde, J. P., Kerr, Y., McAneney, J., and Bonnefond, J.: Surface layer profiles of air temperature and humidity measured from unmanned aircraft, Agronomie, 22, 635-640, 2002.

Junkermann, W.: An ultralight aircraft as platform for research in the lower troposphere: system performance and first results from radiation transfer studies in stratiform aerosol layers and broken cloud conditions, J. Atmos. Ocean. Tech., 18, 934-946, 2001.

Junkermann, W.: The actinic UV-radiation budget during the ESCOMPTE campaign 2001: results of airborne measurements with the microlight research aircraft D-MIFU, Atmos. Res., 74, 461-475, 2005.
Kaimal, J. and Finnigan, J.: Atmospheric Boundary Layer Flows: Their Structure and Measurement, Oxford University Press, 1994.

Kalogiros, J. A. and Wang, Q.: Calibration of a radome-differential GPS system on a twin otter research aircraft for turbulence measurements, J. Atmos. Ocean. Tech., 19, 159-171, 2002a.

Kalogiros, J. A. and Wang, Q.: Aerodynamic effects on wind turbulence measurements with research aircraft, J. Atmos. Ocean. Tech., 19, 1567-1576, 2002 b.

Khelif, D., Burns, S. P., and Friehe, C. A.: Improved wind measurements on research aircraft, J. Atmos. Ocean. Tech., 16, 860-875, 1999.

Leise, J. A. and Masters, J. M.: Wind measurement from aircraft, Tech. rep., United States Department of Commerce, National Oceanic and Atmospheric Administration, Aircraft Operations Center, MacDill Air Force Base, 1993.

Lenschow, D. H.: Aircraft measurements in the boundary layer, in: Probing the Atmospheric Boundary Layer, American Meteorological Society, Boston, Massachusetts, USA, 39-55, 1986.

Mahrt, L.: Surface Heterogeneity and Vertical Structure of the Boundary Layer, Bound.-Lay. Meteorol., 96, 33-62, 2000.

Mahrt, L., Vickers, D., and Sun, J.: Spatial variations of surface moisture flux from aircraft data, Adv. Water Res., 24, 11331141, 2001.

Mauder, M., Desjardins, R. L., and MacPherson, I.: Creating surface flux maps from airborne measurements: application to the Mackenzie area GEWEX study MAGS 1999, Bound.-Lay. Meteorol., 129, 431-450, 2008.

Steinfeld, G., Letzel, M. O., Raasch, S., Kanda, M., and Inagaki, A: Spatial representativeness of single tower measurements and the imbalance problem with eddy-covariance fluxes: results of a large-eddy simulation study, Bound.-Lay. Meteorol., 123, 77-98, 2007.

Tjernström, M. and Friehe, C. A.: Analysis of a radome air-motion system on a twin-jet aircraft for boundary-layer research, J. Atmos. Ocean. Tech., 8, 19-40, 1991.

Trenkle, F. and Reinhardt, M.: In-flight temperature measurements, vol. 2 of Advisory Group for Aerospace Research and Development: Flight Test Instrumentation Series, North Atlantic Treaty Organization, Neuilly-sur-Seine, France, 1973.

van den Kroonenberg, A., Martin, T., Buschmann, M., Bange, J., and Vorsmann, P.: Measuring the wind vector using the autonomous mini aerial vehicle M2AV, J. Atmos. Ocean. Tech., 25, 1969-1982, 2008.

Vickers, D. and Mahrt, L.: Quality control and flux sampling problems for tower and aircraft data, J. Atmos. Ocean. Tech., 14, 512526, 1997.

Visbal, M. R. and Shang, J. S.: Investigation of the flow structure around a rapidly pitching airfoil, AIAA J., 27, 1044-1051, 1989.

Williams, A. and Marcotte, D.: Wind measurements on a maneuvering twin-engine turboprop aircraft accounting for flow distortion, J. Atmos. Ocean. Tech., 17, 795-810, 2000.

Wyngaard, J. C.: The effects of probe-induced flow distortion on atmospheric-turbulence measurements, J. Appl. Meteorol., 20, 784-794, 1981. 